\title{
Robust multi-objective optimization of a renewable based hybrid power system
}

\author{
Justo José Roberts ${ }^{\mathrm{a}, \mathrm{b}, *}$, Agnelo Marotta Cassula ${ }^{\mathrm{a}}$, José Luz Silveira ${ }^{\mathrm{b}}$, Edson da Costa Bortoni ${ }^{\mathrm{c}}$, \\ Andrés Z. Mendiburu ${ }^{\mathrm{d}}$

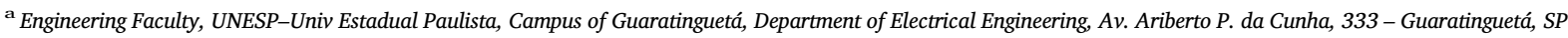 \\ 12510410, Brazil \\ ${ }^{\mathrm{b}}$ Institute of Bioenergy Research, IPBEN-UNESP Guaratinguetá, Brazil \\ ${ }^{\mathrm{c}}$ Engineering Faculty, Itajubá Federal University - UNIFEI, Brazil \\ d Engineering Faculty, UNESP-Univ Estadual Paulista, Campus of Guaratinguetá, Energy Department, Av. Ariberto P. da Cunha, 333 - Guaratinguetá, SP 12510410, \\ Brazil
}

\section{H I G H L I G H T S}

- Probabilistic simulation-based multi-objective optimization approach for hybrid power systems.

- Study the uncertainties of renewable resources availability, load demand, and components failure.

- Post-optimization sensitive analysis leads to unfeasible solutions.

- Optimization with uncertainties implies higher costs for the same level of reliability.

- Useful decision making tool to design optimum and robust power systems.

\section{A R T I C L E I N F O}

\section{Keywords:}

Hybrid power systems dimensioning

Genetic Algorithm

Probabilistic simulation

Uncertainty

Renewable energy

\begin{abstract}
A B S T R A C T
This paper proposes a probabilistic simulation-based multi-objective optimization approach for dimensioning robust renewable based Hybrid Power Systems. The method integrates an Optimization Module based on a multi-objective Genetic Algorithm, an Uncertainty Module that uses Latin Hypercube Sampling method and Monte Carlo Simulation to generate uncertainty scenarios and a Simulation Module to simulate the power system under real operating conditions. Uncertainties considered include the renewable resources availability, the load demand, and the probability of the components' failure. The performance of the proposed approach was assessed in a rural community of the Amazonian region of Brazil. Results show that a system configuration with the same level of reliability as in the deterministic scenario implies a higher economic cost; however, the configurations obtained probabilistically represent feasible robust solutions and guarantee a reliable source of generation. The proposed optimization method constitutes a useful decision making tool for dimensioning hybrid power systems that require both optimality and robustness.
\end{abstract}

\section{Introduction}

Brazil has increased the electrification rate from $79.9 \%$ in 1996 to $99.6 \%$ in 2014 . Nonetheless, this percentage falls down to $89.7 \%$ in the rural areas, particularly the Northern Amazon region presents the most precarious service with an electrification rate of $61.5 \%$ [1]. In these remote areas, the energy supply through the conventional electric grid is prohibitive due to the high costs derived from the difficult accessibility and the low returns related to the small power demand. These isolated rural communities use off-grid power generation systems which generally consist of internal combustion engines coupled with electric generators [2]. However, running generators in remote areas is not trivial. There are difficulties involved, such as the cost of fuel, the logistics of transportation and storage, and the constant need for maintenance. Furthermore, is necessary to consider the environmental issues related to fossil fuels combustion and consequent greenhouse gas emissions [3].

One alternative to meet the energy demand in isolated communities

\footnotetext{
* Corresponding author at: Engineering Faculty, UNESP-Univ Estadual Paulista, Campus of Guaratinguetá, Department of Electrical Engineering, Av. Ariberto P. da Cunha, 333 Guaratinguetá, SP 12510410, Brazil.

E-mail address: justo@feg.unesp.br (J.J. Roberts).
} 


\section{Nomenclature}

Abbreviations

ANEEL Brazilian Electricity Regulatory Agency

BT battery bank

CC cycle charging dispatch strategy

CONV DC/AC converter

DF defined by the user dispatch strategy

DG diesel generator

DIC interruption duration per consumer unit [hour/year]

FIC interruption frequency per consumer unit [int/year]

HPS hybrid power system

$\mathrm{L}_{\mathrm{AC}} \quad$ AC load

LCOE levelized cost of energy [\$/kWh]

LF load following dispatch strategy

LPS loss of power supply [kW]

LPSP loss of power supply probability [\%]

NPVC Net Present Value of costs [\$]

NSGA-II Nondominated Sorting Genetic Algorithm II

PF pareto front

PR performance ratio of the photovoltaic array

PV solar photovoltaic generator

STC standard test conditions

WT wind power generator

Symbols

$C_{\text {icap } j} \quad$ initial capital cost of the jth component [\$]

$C_{\text {level,tot }}$ total levelized cost [U\$S/year]

$C_{o \& m, j} \quad$ operation and maintenance cost jth component [\$/year]

$C_{\text {rep }, j} \quad$ replacement cost of the jth component [\$]

$C R F(\cdot)$ capital recovery factor

(det.) deterministic

DownTimerepair/substitution time [hour]

$d_{r} \quad$ real discount rate [\%]

Ec dispatch strategy

$E c_{\text {min }}, E c_{\text {max }}$ range of possible dispatch strategies

$E M \mathrm{CO}_{2}$ amount of pollutant emissions $\left[\mathrm{kgCO}_{2-\mathrm{eq}} /\right.$ year $]$

$E M \mathrm{CO}_{2, a d m}$ admissible amount of pollutant emissions $\left[\mathrm{kgCO}_{2 \text {-eq }} /\right.$ year]

$F_{0} \quad$ fuel curve intercept coefficient $[\mathrm{L} / \mathrm{h} / \mathrm{kW}]$

$F_{1} \quad$ slope coefficient $[\mathrm{L} / \mathrm{h} / \mathrm{kW}]$

$F_{d g} \quad$ fuel consumption of the diesel generator [L/h]

$F_{d g, a d m}$ admissible fuel consumption of the diesel generator [L/ year]

$f_{\text {exess }} \quad$ energy excess [\%]

$f_{\text {exess,adm }}$ admissible energy excess [\%]

$f_{m}(\vec{x}) \quad$ objective function of order $m$

$f_{p v} \quad$ power reduction factor [\%]

$f_{\text {ren }} \quad$ renewable fraction [\%]

$f_{\text {ren,min }} \quad$ minimum renewable fraction [\%]

$g_{j}(\vec{x}) \quad$ greater-than-equal-to constraint of order jth

$h_{k}(\vec{x}) \quad$ equality constraint of order kth

LPSP $_{a d m} \quad$ Admissible loss of power supply probability [\%]

$L T_{p r o j} \quad$ life time of the project [year]

$M \quad$ number of objectives

maxGen maximum number of generations of the Genetic Algorithm

$M T B F_{i} \quad$ mean times between failure of the ith component [hour]

$M T T R_{i} \quad$ mean time to repair of the ith component [h]

$n \quad$ number of decision variables

$N_{\text {best }} \quad$ best individuals in the population

$N_{b t p} \quad$ number batteries in parallel of the battery bank

$N_{\text {conv }} \quad$ number of converters

$N_{d g} \quad$ number of diesel generators
$N_{p v} \quad$ number of photovoltaic modules

$N P V_{C, \text { adm }}$ Admissible Net Present Value [\$]

$N_{\text {samp }} \quad$ number of samples

$N_{w t} \quad$ number of wind turbines

$N_{j, \text { min }}, N_{j, \text { max }}$ minimum and maximum number of the jth component

$p \quad$ DC load fraction of converter

$p_{0}, \kappa \quad$ characteristic parameters of converter model

$P_{d c, \text { rated }} \quad$ converter DC rated power $[\mathrm{kW}]$

$P_{d g} \quad$ diesel generator instantaneous power output $[\mathrm{kW}]$

$P_{d g r} \quad$ diesel generator rated power $[\mathrm{kW}]$

$P_{\text {input }} \quad$ converter DC power input $[\mathrm{kW}]$

$P_{\text {load }} \quad$ power consumed by the load $[\mathrm{kW}]$

popSize population size of the GA

$P_{p v} \quad$ power delivered by the PV array [kW]

$P O A$ solar irradiance incident upon the plane of the array [kW/ $\mathrm{m}^{2}$ ]

$P O A_{S T C}$ incident solar irradiance at Standard Test Conditions [kW/ $\mathrm{m}^{2}$ ]

$p_{r} \quad$ recombination probability [\%]

(prob.) probabilistic

$P_{w t} \quad$ power output of the wind turbine $[\mathrm{kW}]$

$P_{w t, r} \quad$ wind turbine rated power [kW]

SOC state of charge of the battery bank [\%]

$S O C_{\text {min }}$ minimum state of charge of the battery bank [\%]

Sol(det.) solutions obtained with the deterministic algorithm

Sol(prob. ) solutions obtained with the probabilistic algorithm

$t \quad$ time variable [h]

$T \quad$ period of time considered for analysis [h]

$T_{a} \quad$ ambient temperature $\left[{ }^{\circ} \mathrm{C}\right]$

$T_{b t} \quad$ model of battery

$T_{c} \quad$ temperature of the photovoltaic cell $\left[{ }^{\circ} \mathrm{C}\right]$

$T_{c, S T C}$ temperature of the photovoltaic cell at Standard Test Conditions $\left[{ }^{\circ} \mathrm{C}\right]$

$T_{\text {conv }} \quad$ model of converter

$T_{d g} \quad$ model of diesel generator

$T_{j} \quad$ model of jth component

$T_{j, \min }, T_{j, \max }$ range of possible models for the jth component

$T_{p v} \quad$ model of photovoltaic module

$T_{w t} \quad$ model of wind turbine

$u \quad$ instantaneous wind speed $[\mathrm{m} / \mathrm{s}]$

$U_{c i}, U_{c o}, U_{r}$ cut-in, cut-out and rated wind speeds $[\mathrm{m} / \mathrm{s}]$

UpTime operation time [h]

$\vec{x}_{j} \quad$ decision vector of order jth

$\vec{x} \quad$ decision vector

$x_{n}^{(L)}, x_{n}^{(U)}$ lower and upper limit of the nth variable

$Y_{p v} \quad$ rated capacity of the PV array [kW]

Greek symbols

$\begin{array}{ll}\alpha_{p} & \text { temperature coefficient of power }\left[\% /{ }^{\circ} \mathrm{C}\right] \\ \delta_{d} & \text { daily perturbation factor } \\ \delta_{h} & \text { hourly perturbation factor } \\ \delta_{\text {load }} & \text { perturbation factor for load profile } \\ \Delta t & \text { time step used for calculation [h] } \\ \varepsilon_{j}\left(\mu_{i}, \sigma_{i}\right) & \text { discrete samples of stochastic variables } \\ \varphi_{i}(t) & \text { time-dependent phenomena } \\ \Phi_{i}(t) & \text { component operation history } \\ \lambda_{f_{i}} & \text { failure rate of the ith component }[1 / \mathrm{h}] \\ \lambda_{r_{i}} & \text { repair rate of the ith component }[1 / \mathrm{h}] \\ \eta_{\text {conv }} & \text { efficiency of the AC/DC converter }[\%] \\ \xi & \text { vector of random variables } \\ \sigma & \text { Variance of the probability distribution } \\ \sigma_{\text {day,noise }} & \text { standard deviation of the daily noise factor }[\mathrm{kW}] \\ \sigma_{\text {hour,noise }} & \text { standard deviation of the hourly noise factor }[\mathrm{kW}] \\ \theta_{i}(t) & \text { uncertain parameter ith variable } \\ \Theta_{j}(t) & \text { matrix of energy balance results of jth order }\end{array}$


$\mu \quad$ mean of the probability distribution

$\mu(\mathrm{Sol})^{\text {Pareto (det.) }}$ mean of the deterministic solutions simulated

probabilistically

is through autonomous power systems based on renewable energies, especially the so called Hybrid Power Systems (HPS), which combine two or more renewable sources to power supply different loads [4]. In these systems solar photovoltaic and wind are the most employed renewable energy sources due its high technological maturity and low implementation costs [5]. Backup generation is almost exclusively carried out by generators running on diesel oil [6], but some works assess the possibility of using biodiesel [7] or synthesis gas to fuel the generator [8]. Mini and micro-hydroelectric generation is an attractive technology due to its high efficiency and low operation and maintenance costs [9], however this technology is only viable in certain regions where the resource is available. Few studies consider gas-fired micro-turbines as generation source, being this technology still expensive for remote isolated locations [10]. Lead-acid battery is the most common energy storage device used in autonomous power systems at present [11]. Its success is due to its maturity, low cost, long lifespan, fast response, and low self-discharge rate. In recent years hydrogen storage systems have become a promising technique to store large volumes of energy [12]. However, the cost of generating and storing hydrogen still limits its application. Some works study alternative technologies such as thermal storage [13] or water pumping [14].

When properly designed, the HPS present technical, economic and environmental benefits in comparison to single-source-based renewable power systems or traditional power systems [15]. However, the optimal design of HPS is a complex task due to the stochastic behavior of: (a) the renewable resources' availability and load demand, (b) the non-linear characteristic of the system's components, and, (c) the high interaction between operational variables [16]. From the moment an isolated rural community has access to electricity, the users become dependent on it, and interruptions in the service may lead to catastrophic consequences to them. Therefore, there is a need for a method to design robust power generation systems that ensure the electricity supply for these communities.

The optimal sizing of HPS is a well addressed issue in the area of power system research. Various classical techniques have been proffered by researchers to solve this problem, among them analytical methods [17], graphical construction methods [18], probabilistic methods [10] and iterative methods [6]. The classical optimization techniques present the disadvantage that only one design criterion can be considered, typically the economic or the technical [19]. Modern optimization algorithms enable to consider multiple optimization criteria simultaneously, such as the environmental, the social and the geographical [20]. Among these techniques Metaheuristic algorithms provide a worthy tool for the design of hybrid power systems without the need of extensive long-term data and with the ability to handle multi-objective optimization problems efficiently [21].

One important aspect in the design of HPS is uncertainties in the input variables. Uncertainties related to the operation of the HPS requires their implicit consideration. The most widespread method consists in performing a deterministic optimization and then exploring the influence of uncertain parameters through a sensitivity analysis [22]. This approach is most suitable for problems with few uncertain parameters, were various possible combinations of deterministic values can be tested. For large-scale problems, programming this number of combinations may become extremely large. Regarding the sources of uncertainty, it is observed in the literature that most of the works consider the stochastic nature of the renewable resources (solar and wind) $[23,24]$, and in some cases the variability of the load demand $[10,25]$. Fewer works heed the components availability in the uncertainty model $[26,27]$. In this way, a sensitive source of uncertainty for the performance of the HPS, such as the components failure rate, is neglected. None of the works in the literature consider the three above mentioned sources of uncertainty simultaneously.

To enable optimum performance of HPS, all sources of uncertainties should be considered during the design stages of such systems, along with the complex interactions that unravel as numerous components with diverse characteristics involved in the operation of the renewablebased power generation system.

To address this problem, the present work proposes a probabilistic simulation-based optimization method to design a HPS. The method combines two desirable features, multi-objective optimization and uncertainty quantification. The uncertainties considered are related to the renewable resources availability, the load demand, and the probability of the components' failure. The incorporation of these three sources of
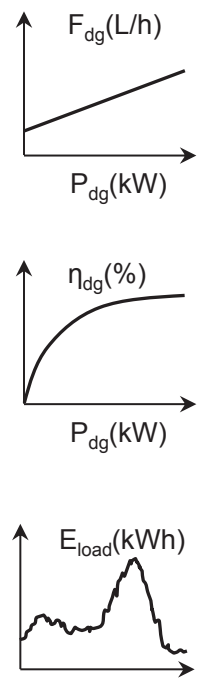

$\mathrm{t}(\mathrm{h})$
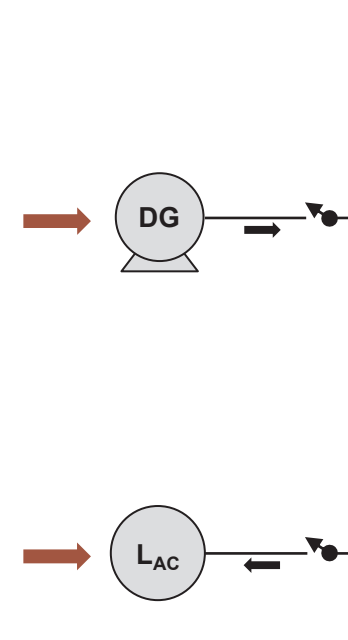
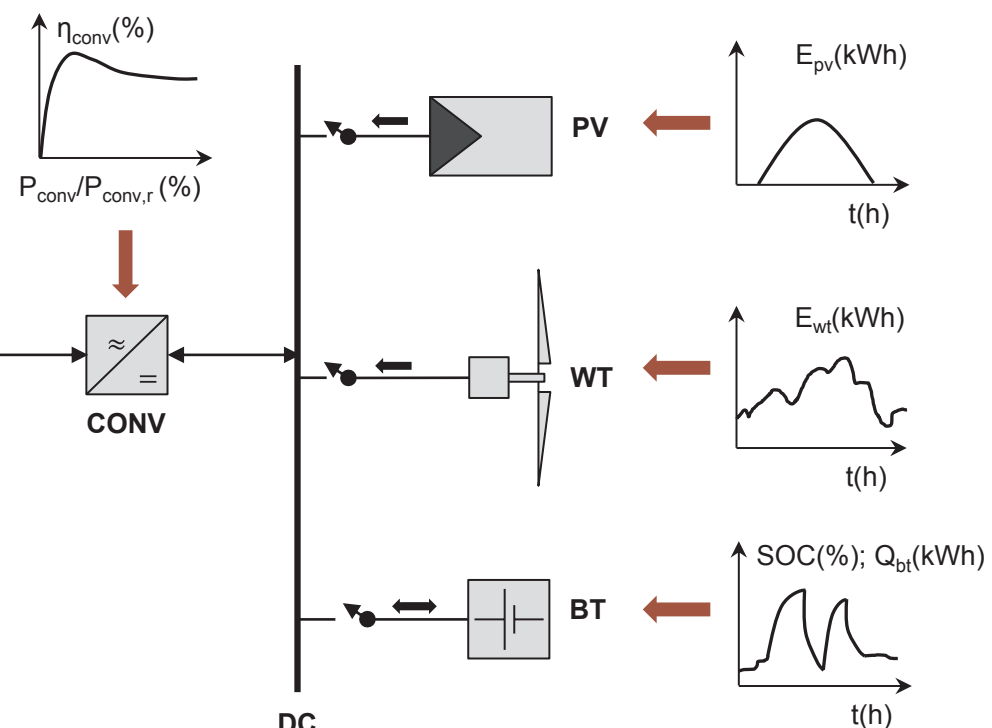

Fig. 1. Typical wind-solar-diesel-battery stand-alone HPS configuration. 


\section{(1) START}

Input parameters: component characteristics, renewable resources, load, GA parameters

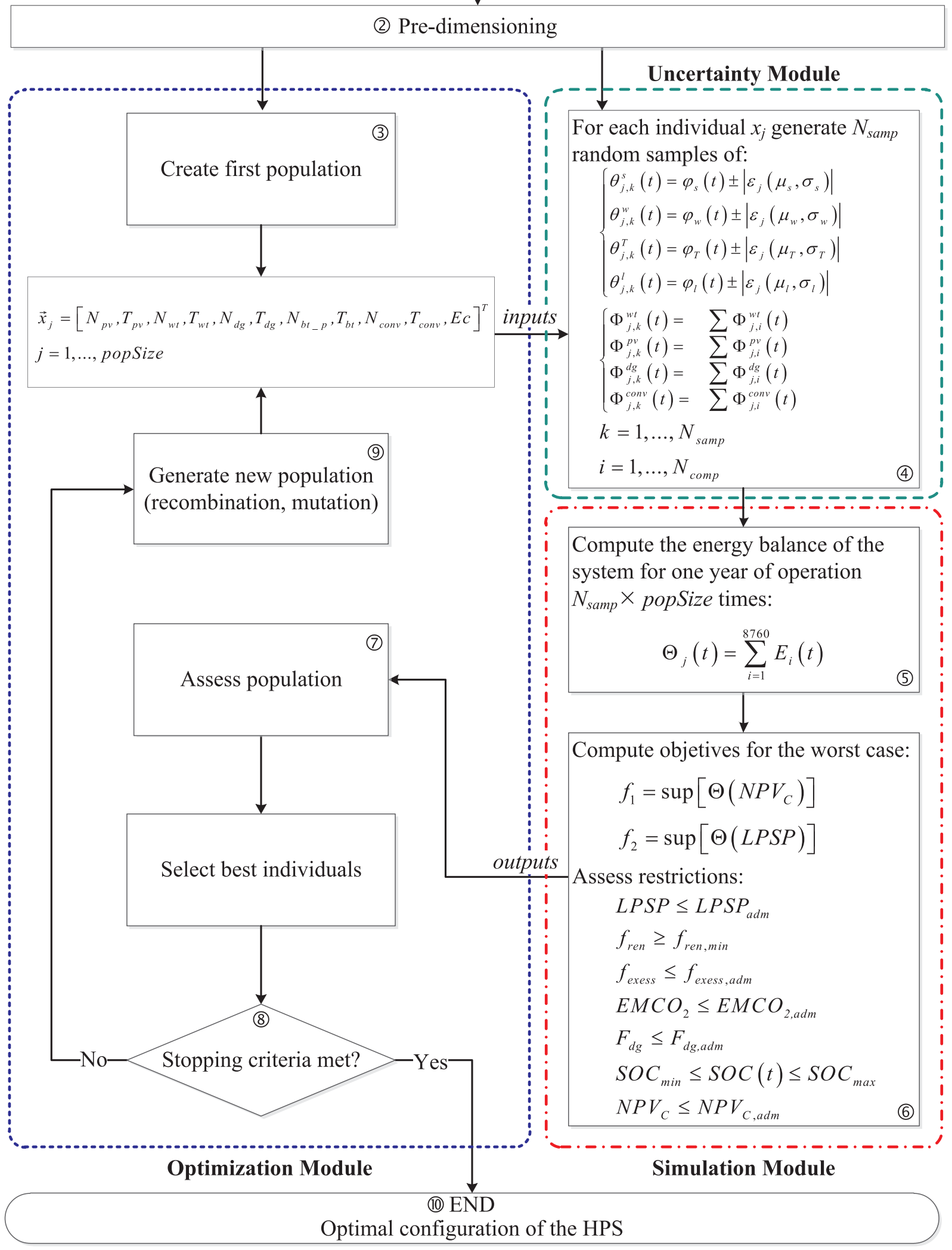

Fig. 2. Flowchart of the proposed probabilistic simulation-based optimization approach. 
uncertainty within the optimization process of the HPS constitutes the main contribution of the present work.

The proposed algorithm comprises three modules which interact to find the best configuration of the HPS, the Optimization Module, the Simulation Module and the Uncertainty Module. In this way the method allows to design a HPS with the lowest possible cost, and that is able to extract the maximum potential of the renewable resources, and most important, to guarantee a reliable electrical supply, through the correct dimensioning of the battery bank and the backup generator.

The rest of the article is organized as follows. Section 2 presents the methodological basis of the present research, discussing the proposed probabilistic simulation-based optimization approach, presenting the simulation, uncertainty and optimization modules that together compose the HPS design methodology. Section 3 describes the case study. In Section 4 the results of the implementation of the design methodology are presented comparing the deterministic and the probabilistic optimization approaches. Concluding remarks are given in Section 5 .

\section{Materials and methods}

The renewable-based hybrid power system studied in this work is presented in Fig. 1 and comprises an array of photovoltaic modules (PV), a wind turbine (WT), a bank of lead-acid batteries (BT), a diesel generator (DG), a DC/AC converter (CONV) and the $\mathrm{AC}$ load $\left(\mathrm{L}_{\mathrm{AC}}\right)$ to be served. Fig. 1 also depicts the non-linear characteristic of the components operation, and, the stochastic nature of the renewable resources and the load which must be integrated in the system's sizing calculations.

The complexity of the optimization problem studied here makes impossible to know in advance the structure of the objective function and an analytical expression of this function cannot be deduced. Therefore, there is a necessity to derive the objective function from the outputs of simulation runs. For this, it is proposed the probabilistic simulation-based optimization approach depicted in Fig. 2. The main algorithm is formed by three sub-algorithms, the Optimization Module, the Uncertainty Module and the Simulation Module.

The input parameters, step (1) in Fig. 2, are the technical and economic characteristics of the HPS components; the characteristics of the renewable resources and the load to be served; the parameters of the GA; and the uncertainties considered. In step (2), the algorithm sets the maximum and minimum limits of the decision variables to bound the search space and to reduce the simulation time. For this, we adopted the pre-dimensioning method suggested by [28]. Step (3) consists in randomly generate the first generation of the GA, $\vec{x}_{j}$, formed by popSize individuals. In step (4), the uncertainty scenarios are generated; for each individual in the population a total of $N_{\text {samp }}$ samples for the availability of renewable resources and load demand scenarios are generated using the method explained in Section 2.2. Also, there are $N_{\text {samp }}$ generated from chronological state transition processes for the components subjected to failure. In step (5), each individual in the population is simulated $N_{\text {samp }}$ times under the uncertainty scenarios generated in step (4). All in all, the algorithm performs a total of $N_{\text {samp }} \times$ popSize simulations of the HPS in each generation of the GA. Thus, for each individual in the population it is obtained a matrix of energy balance results $\Theta_{j}(t)$. With this information, the performance of the system is assessed in step (6). The result is a set of stochastic indices, that is, a probability distribution for each performance index calculated. At this point it is necessary to apply a method to obtain a deterministic value from the probabilistic indices derived from the simulations. We adopted the minimax method presented in Eq. (1) [29]:

$\min _{F}\left[\sup _{\Xi} f_{1}(\vec{x}, \xi), \sup _{\Xi} f_{2}(\vec{x}, \xi), \ldots, \sup _{\Xi} f_{m}(\vec{x}, \xi)\right]^{T}$

where $f_{m}(\vec{x}, \xi)$ are the objective functions; $\xi \in \Xi$ is the vector of random variables; and $\sup (\cdot)$ indicates the worst-case scenario for the specific objective function. In step (7), the algorithm checks the feasibility of each solution according to the constraints imposed by the user, each individual in the population gets a level of aptitude depending on the value of the objective functions and the amount of constraints violated. Thus, the best individuals (the fittest) are selected to move on to the next generation. Next, in step (8), the stopping criteria are checked, and if not met, the population undergoes the GA evolution process through recombination and mutation (step (9). The population is updated with the new individuals, which are expected to be better than those in the previous generation. At this point, the algorithm completes a full generation cycle. After updating the population, the individuals are sent back to the simulation module to compute the objective function and restrictions and back to the optimization module again. This cycle is repeated until the termination criteria are met. In the final step (10), the algorithm returns a set of non-dominated solutions that can be considered "robust" since they were obtained considering the uncertainties in the optimization process.

\subsection{Optimization module}

The optimization module is responsible for searching the best configuration of HPS among the universe of possible configurations, that is, it needs to solve the optimization problem as defined in equation (2).

$$
\begin{array}{rll}
\text { Minimize } & f_{m}(\vec{x}) & m=1,2, \ldots, M \\
\text { Subjected to } & g_{j}(\vec{x}) \geqslant 0 & j=1,2, \ldots, J \\
& h_{k}(\vec{x})=0 & k=1,2, \ldots, K \\
& x_{n}^{(L)} \leqslant x_{n} \leqslant x_{n}^{(U)} & i=1,2, \ldots, n
\end{array}
$$

where $M$ is the number of objective functions $f_{m}(\vec{x})=\left(f_{1}(\vec{x}), f_{2}(\vec{x}), \ldots, f_{M}(\vec{x})\right)^{T} ; g_{j}(\vec{x})$ is the jth greater than or equal to constraint; $h_{k}(\vec{x})$ is the kth equality constraint; and $\left[x_{n}^{(L)}, x_{n}^{(U)}\right]$ is the range of variation of the nth variable and $n$ is the number of decision variables.

\subsubsection{Decision vector}

The decision variables correspond to the number of components of the HPS, the model of the components and the dispatch strategy. The system studied comprises solar, wind and diesel generation with battery storage, thus $\vec{x}$ results in an 11-dimension vector:

$\vec{x}=\left[x_{i}\right]^{T}=\left[N_{w t}, T_{w t}, N_{p v}, T_{p v}, N_{d g}, T_{d g}, N_{b t p}, T_{b t}, N_{\text {conv }}, T_{\text {conv }}, E c\right]^{T}$

where $N_{w t}, N_{p v}, N_{d g}, N_{b t p}$ and $N_{c o n v}$ are the number of wind turbines, PV modules, diesel generators, batteries in parallel (of the battery bank) and converters, respectively. The $T_{w t}, T_{p v}, T_{d g}, T_{b t}$ and $T_{\text {conv }}$ are the model of wind turbine, PV module, diesel generator, battery and converter, respectively. Finally, $E c$ is the dispatch strategy.

\subsubsection{Objective functions}

The optimization of the HPS considers two objective functions. One of them is an economic objective computed through the Net Present Value of costs $\left(N P V_{C}\right)$ according to equation (4):

$N P V_{C}=\frac{C_{\text {level,tot }}}{C R F\left(d_{r}, L T_{\text {proj }}\right)}$

where $C_{\text {level,tot }}$ (\$/year) is the total levelized cost, $C R F(\cdot)$ is the capital recovery factor, $d_{r}(\%)$ is the real interest rate (discount rate) and $L T_{p r o j}$ (year) is the lifespan of the project.

The second objective is related to the reliability of the system, and is computed through the Loss of Power Supply Probability shown in equation (5):

$L P S P=\sum_{t=1}^{T} \operatorname{LPS}(t) / \sum_{t=1}^{T} P_{\text {load }}(t) \Delta t$

where $\operatorname{LPS}(t)$ is the Loss of Power Supply $(\mathrm{kW})$ when the energy generated by the HPS results less than the load demand, $P_{\text {load }}(t)$ is the 
power consumed by the load at hour $t(\mathrm{~kW}), T$ is the period of time considered for analysis $(8760 \mathrm{~h})$ and $\Delta t$ is the time step used for calculation $(\Delta t=1 \mathrm{~h})$.

\subsubsection{Constraints}

The problem constraints are shown in equations (6)-(15). The constraints consider the following:

(a) The admissible value of LPSP, to avert unfeasible solutions (6).

(b) The admissible energy excess, $f_{\text {exess }}$, which is the surplus electrical energy that must be dumped because it cannot be used to serve the load or charge the batteries (7).

(c) The minimum renewable fraction, $f_{\text {ren }}$, which is the ratio of the energy generated by the renewable sources to the total energy generated by the HPS (8).

(d) The maximum fuel consumption of the diesel generator, $F_{d g}(9)$.

(e) The maximum amount of pollutant emissions, $\mathrm{EMCO}_{2}$ (10).

(f) The state of charge of the battery, SOC, which must be kept within minimum and maximum levels (11).

(g) The admissible $N P V_{C}$ which can be specified (12).

(h) The constraints related to the upper and lower limits of the decision variables (13), (14) and (15).

$g_{1}(\vec{x}) \equiv L P S P \leqslant L P S P_{a d m}$

$g_{2}(\vec{x}) \equiv f_{\text {exess }} \leqslant f_{\text {exess }, a d m}$

$g_{3}(\vec{x}) \equiv f_{\text {ren,min }} \leqslant f_{\text {ren }}$

$g_{4}(\vec{x}) \equiv F_{d g} \leqslant F_{d g, a d m}$

$g_{5}(\vec{x}) \equiv \mathrm{EMCO}_{2} \leqslant \mathrm{EMCO}_{2, \text { adm }}$

$g_{6}(\vec{x}) \equiv S O C_{\min } \leqslant S O C(t) \leqslant S O C_{\max }$

$g_{7}(\vec{x}) \equiv N P V_{C} \leqslant N P V_{C, a d m}$

$N_{j, \min } \leqslant N_{j, i} \leqslant N_{j, \max }$

$T_{j, \min } \leqslant T_{j, i} \leqslant T_{j, \max }$

$E c_{\min } \leqslant E c \leqslant E c_{\max }$

\subsubsection{Optimization algorithm}

The HPS dimensioning problem was solved using a multi-objective optimization algorithm based on GA, i.e., the Non-dominated Sorting Genetic Algorithm II (NSGA-II) [30]. The NSGA-II has proven good performance in solving complex problems due to the incorporation of three mechanisms: (i) elitism, to prevent the loss of good solutions once they are found; (ii) fast nondominated sorting, selection mechanism that classifies the individuals at different levels according to the Pareto dominance; and (iii) crowding distance assignment, mechanism that promotes the diversity of the population.

In the present work, the original NSGA-II algorithm was adapted to allow its integration in the probabilistic simulation-based optimization algorithm.

\subsection{Uncertainty module}

The Optimization Module selects a system configuration defined by a number of wind turbines, PV modules, backup generators, batteries in the battery bank and converters. This HPS configuration must be simulated under real operating conditions. Thus, to better represent the annual variations of the meteorological variables, the variations in the load and the failure probability of the system's components, some scenarios are generated where uncertainties are introduced around the original value. These uncertainties are represented stochastically through the use of probability distribution functions. There are two sources of uncertainties:

\subsubsection{External uncertainties}

Involve the variations related to the meteorological variables and load demand. Considering that $\varphi_{i}(t)$ represents the time-dependent phenomena such as solar irradiance $(i=s)$, wind speed $(i=w)$, ambient temperature $(i=T)$ and load demand $(i=l)$ derived from historical measurements; the deviations from the observed behavior of the real phenomenon can be approximated through the incorporation of a stochastic uncertainty model. These deviations can be expressed by the assignment of a probability distribution in the predictions of new series from the original ones. A probability distribution with mean $\mu$ and variance $\sigma$ is a continuous function that can be approximated by a set of randomly drawn, discrete samples $\varepsilon_{j}\left(\mu_{i}, \sigma_{i}\right)$ with $j=1, \ldots, N_{\text {samp }}$ and $i=s, w, T, l$. Such samples associated to the values of $\varphi_{i}(t)$ represent the uncertain parameter $\theta_{i}(t)=\varphi_{i}(t) \pm\left|\varepsilon_{j}(\mu, \sigma)\right|$. It is assumed that the interannual variation of the mean values for wind speed, solar irradiance, temperature and load demand can be represented by a Gaussian probability distribution function [31,32].

Thus, knowing the annual mean and the standard deviation of the uncertain variables it is possible to carry out a probabilistic analysis using a suitable sampling method, in this case the Latin Hypercube Sampling was used [33].

To generate the uncertain scenarios the algorithm draws a total of $N_{\text {samp }}$ random samples from the probability distribution $\varepsilon_{j}\left(\mu_{i}, \sigma_{i}\right)$. Each hourly series of resources and load demand is derived from the original series, but its average value will be obtained according to the Gaussian probability distribution. When the HPS is simulated under these probabilistically generated conditions, the result is a series of probability distribution functions related to each performance index.

In addition to external uncertainties, the method also includes discrete uncertainties, related to the components' failure probability.

\subsubsection{Discrete uncertainties}

Are related to the unavailability of the components subjected to failure. To represent these uncertainties it is necessary to generate chronological state transition processes (outage history) of the HPS components using the sequential Monte Carlo simulation technique. In this approach, chronological component state transition processes for all the HPS components are first simulated by sampling. Then, the chronological state transition process of the system is created by combining the chronological component state transition processes. In a twostate component representation, these are the operating and repair state duration distribution functions and are usually assumed to be exponential [34]. The outage history of each component is generated by simulating its operation and repair time using equations (16) and (17), respectively.

UpTime $_{i}=-M T B F_{i} \times \ln \left(U_{i}\right)$

DownTime $_{i}=-M T T R_{i} \times \ln \left(U_{i}\right)$

where $M T B F_{i}=1 / \lambda_{f_{i}}$ and $M T T R_{i}=1 / \lambda_{r_{i}}$ are the mean time between failure and mean time to repair of the ith component, respectively; $\lambda_{f_{i}}$ and $\lambda_{r_{i}}$ are the failure rate and repair rate of the ith component; and $U_{i}$ is a uniformly distributed random number between $[0,1]$.

The economic and reliability indices calculated for each configuration of the HPS and used by the Optimization Module to compare the performance of the different configurations, are the average value obtained from the $N_{\text {samp }}$ scenarios.

\subsection{Simulation module}

The purpose of the Simulation Module is to assess the objective functions and the performance indices for each HPS configuration for one year of operation. It is able to run simulations for any HPS 
configuration interconnecting the components shown in Fig. 1. The output of the Simulation Module is a series of performance indices related to economic, reliability and environmental aspects. This information is then used by the Optimization Module to guide the search for the best HPS configuration.

After the Optimization Module selects a particular system configuration, defined by the number and model of components and the dispatch strategy, the Simulation Module simulates that system operation considering time series of wind speed, solar irradiance, ambient temperature and load demand. In the original series, external uncertainties and discrete uncertainties are considered as described in Section 2.2 .

The algorithm is based on the hourly $(\Delta t=1 \mathrm{~h})$ simulation of a full year of operation of the HPS, this time interval is suitable for long-term simulations [35]. The operation of the HPS depends on the selected dispatch strategy, whose function is to manage the interaction between the different components of the system. In each simulation interval $(\Delta t)$ the dispatch strategy evaluates the input information related to the renewable resources availability, the load demand and the state of charge of the storage system. It then decides about the energy flow in the system, defining which components should be turned off, which ones should be disconnected, where the energy excess should be stored and activates the dissipative loads when it is necessary to optimize the system performance. At the end of each simulation interval the energy balance (sum of generation and sinks) should be zero, considering losses and energy surplus/deficit, when applicable.

The components' mathematical models included in the Simulation Module are presented below, more detailed information can be found in the cited references.

\subsubsection{Solar photovoltaic power system (PV)}

The mathematical representation used to estimate the energy generation of the PV system is based on the single point efficiency representation of a PV module proposed by [36]:

$P_{p v}=Y_{p v}\left(\frac{P O A}{P O A_{S T C}}\right)\left[1+\alpha_{p}\left(T_{c}-T_{c, S T C}\right)\right] f_{p v}$

where $P_{p v}(\mathrm{~kW})$ is the power delivered by the PV array; $Y_{p v}(\mathrm{~kW})$ is the rated capacity of the $\mathrm{PV}$ array; $P O A\left(\mathrm{~kW} / \mathrm{m}^{2}\right)$ is the solar irradiance incident upon the plane of the array; $P O A_{S T C}$ is the incident irradiance at STC $\left(1 \mathrm{~kW} / \mathrm{m}^{2}\right) ; \alpha_{p}\left(\% /{ }^{\circ} \mathrm{C}\right)$ is the temperature coefficient of power; $T_{c}$ $\left({ }^{\circ} \mathrm{C}\right)$ is PV cell temperature; $T_{c, S T C}\left({ }^{\circ} \mathrm{C}\right)$ is the cell temperature at STC; and $f_{p v}(\%)$ is a power reduction factor that considers all the non-temperature dependent loses.

The temperature of the photovoltaic cell under operating conditions, $T_{\mathcal{c}}$, is estimated using the modified implicit correlation proposed by [37] and shown in Eq. (19). With this correlation it is possible to estimate de cell temperature with good accuracy and little information.

$T_{c}=T_{a}-1.52567+0.01981336 \cdot P O A-0.000003451 \cdot P O A^{2}$

The POA irradiance is estimated from the global horizontal irradiance, which is generally available from meteorological data. The method applied for this calculation was proposed by [38].

\subsubsection{Wind turbine (WT)}

The energy generated by a WT can be estimated through its power curve, which indicates the power supplied by the WT as a function of the available wind speed. The HPS incorporates three-blade-horizontal axis WT whose power curve can be approximated using the piecewise interpolation function of Eq. (20) [39]:

$$
P_{w t}(u) \begin{cases}0 & u \leqslant U_{c i} \text { ou } u \geqslant U_{c o} \\ a_{1} u^{3}+b_{1} u^{2}+c_{1} u+d_{1} & U_{c i}<u<U_{1} \\ a_{2} u^{3}+b_{2} u^{2}+c_{2} u+d_{2} & U_{1}<u<U_{2} \\ \cdots & \\ a_{n} u^{3}+b_{n} u^{2}+c_{n} u+d_{n} & U_{n-1}<u<U_{n} \\ P_{w t, r} & U_{r}<u<U_{c o}\end{cases}
$$

where $P_{w t}(\mathrm{~kW})$ is the instantaneous output power of the WT at wind speed $u(\mathrm{~m} / \mathrm{s}) ; P_{w t, r}(\mathrm{~kW})$ is the rated output power; $a, b$ and $c$ are the polynomial coefficients of the cubic spline interpolation functions; $U_{c i}$, $U_{r}$ and $U_{c o}$ are the cut-in, rated and cut-out wind speeds, respectively; and $n$ is the number of cubic spline interpolation functions corresponding to $n+1$ value couples (speed, power) of data provided by the manufacturers.

The real power generated by the WT is obtained after applying two corrections to Eq. (20) First, the wind speed must be extrapolated to the WT hub height, this is done through the power law method [40]. Then, a correction factor that considers the variation of air density due to installation site altitude is computed using the method proposed by [41].

\subsubsection{Battery bank (BT)}

The HPS counts with a lead-acid battery bank that helps smooth out the variability of solar and wind power production. The mathematical model used to represent the battery incorporates a performance model and a lifetime model.

The performance model determines the amount of energy that can be absorbed by or withdrawn from the battery bank in each time step. The analytical model called Kinetic Battery Model (KiBaM) was adopted [42]. The battery lifetime model is based on the Ah-throughput approach to calculate the expected lifetime of the battery bank [43].

\subsubsection{Diesel generator $(D G)$}

The diesel generator is a backup power source used as emergency power-supply when the renewable resources are not available and the battery bank is at its lowest state of charge. The generator power output is modeled using the linear function (20):

$F_{d g}=F_{0} \cdot P_{d g r}+F_{1} \cdot P_{d g}$

where $F_{d g}(\mathrm{~L})$ is the DG instantaneous fuel consumption; $P_{d g r}(\mathrm{~kW})$ is the DG rated power; $P_{d g}(\mathrm{~kW})$ is the instantaneous DG output power; $F_{0}(\mathrm{~L} /$ $\left.\mathrm{h} / \mathrm{kW}_{\text {rated }}\right)$ is the fuel curve intercept coefficient; and $F_{1}(\mathrm{~L} / \mathrm{h} / \mathrm{kW})$ is the slope coefficient.

\subsubsection{Converter (CONV)}

The model is capable of representing the converter's efficiency over the full range of operating conditions [44]. The efficiency of the converter when referring to the input power $\left(\eta_{\text {conv }}\right)$ of the device is given by Eq. (21):

$\eta_{\text {conv }}=\frac{p-p_{o}-\kappa p^{2}}{p}$

where $p$ is the DC load fraction given by $p=P_{\text {input }} / P_{d c \text {,rated }} ; P_{\text {input }}(\mathrm{kW})$ is the DC power input; $P_{d c, \text { rated }}(\mathrm{kW})$ is the DC rated power. The parameters $p_{0}$ and $\kappa$ are characteristic to each kind of inverter [44].

\subsubsection{Load model}

Measured hourly load data is seldom available, thus it is necessary to synthetically generate load data from typical daily load profiles, which are easier to obtain. The adopted method [41] initiates by replicating the daily load profile for the whole simulation period (365 days), next some randomness is added on hourly and daily basis to simulate the stochastic nature of electric consumption. This is done by multiplying each hourly value by a factor, $\delta_{\text {load }}=1+\delta_{d}+\delta_{h}$. Where $\delta_{d}$ is the daily perturbation factor, $\delta_{d} \sim U\left(0, \sigma_{\text {day,noise }}\right)$, drawn once per day from a normal distribution with a mean of zero and a standard 
deviation equal to the daily noise input value; and $\delta_{h}$ is the hourly perturbation factor, $\delta_{h} \sim U\left(0, \sigma_{\text {hour, noise }}\right)$, drawn once per hour from a normal distribution with a mean of zero and a standard deviation equal to the hourly noise input value. Further, the algorithm allows specifying a scale factor to account for weekend days and seasonal variations in the load profile.

\subsubsection{Dispatch strategy}

The HPS may operate according to two dispatch strategies: (i) Load following (LF) [45], where the batteries are only charged whenever the renewable power exceeds the primary load, if the batteries cannot supply the load, the DG will operate at rate that produces only enough power to meet the load; (ii) Cycle charging (CC) [45], if the batteries cannot meet the load, the DG runs at maximum power to supply the load and charge the batteries up to a pre-set State of Charge (SOC). The most appropriate dispatch strategy for a given HPS configuration is also an optimization variable.

\subsubsection{Environmental impact}

Although environmental impact is not part of the optimization process, the maximum amount of pollutant emissions is employed as a restriction for the problem. It is assessed through the Life Cycle Analysis methodology [46]. The main indicator used in this analysis is the Global Warming Potential, in $\mathrm{kgCO}_{2}$-eq, representing how much a determined amount of greenhouse gas contributes to global warming. The simulation model estimates the total amount of emissions in the life cycle of the HPS considering the contribution of direct and indirect emissions of all the components.

\subsection{Computational implementation}

The HPS optimization algorithm was implemented in Matlab ${ }^{\circledR}$ platform in the form of a dedicated toolbox. It allows the possibility of running the algorithm using parallel computation to increase the computational performance of very extensive and independent tasks. Implementing the algorithm in an open-architecture software such as Matlab $^{\circledast}$ allows the necessary flexibility to constitute itself as a research tool.

\section{Case study}

The proposed method is used to design a standalone HPS for a rural community located in the Amazonian region of Brazil. The community of Vila Campinas is located in the municipality of Manacapurú, in the state of Amazonas, in the North region of Brazil (see Fig. 3). The community has about 1010 inhabitants and is accessible only by boat, which takes between three to six hours from the nearest city.

Fig. 4(a) presents the community's hourly load profile for the year, that was synthetically generated from the daily electricity consumption profile reported by [47]. It was considered hourly and daily noise factors of $15 \%$, a weekend scale factor of 1.1 and no seasonal scale factor. This resulted in an average energy consumption of $474.9 \mathrm{kWh} /$ day. The daily consumption profile for the different seasons is presented in Fig. 4(b), since no seasonal scale factor was considered the curves are identical. It is a typical rural profile characterized by a fairly constant consumption during most part of the day and a peak of consumption in the evening when the villagers come back home after a working day. This behavior is confirmed by the histogram of Fig. 4(c) where it is observed that lower than the mean levels of power consumption are more frequent.

Hourly measurements of the meteorological variables wind speed and solar irradiance for the case study location were obtained from references $[48,49]$. Fig. 5(a) presents the hourly wind speed distribution for the year and Fig. 5(b) shows the mean daily wind speed profile for the different seasons. The wind resource presents a seasonality behavior with higher wind speed registries during winter and spring

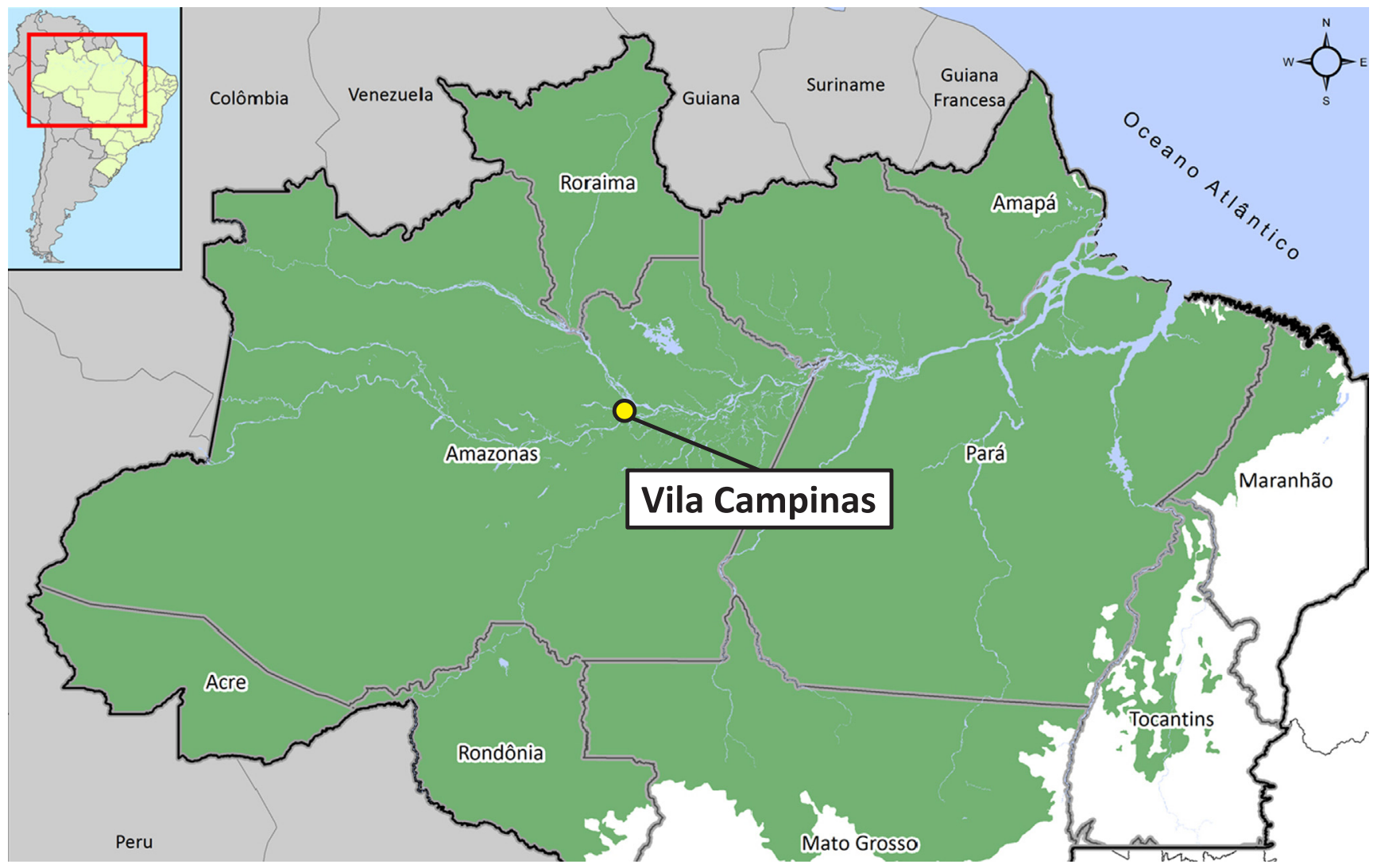

Fig. 3. Geographical localization of the community of Vila Campinas in the Northern Region of Brazil. 

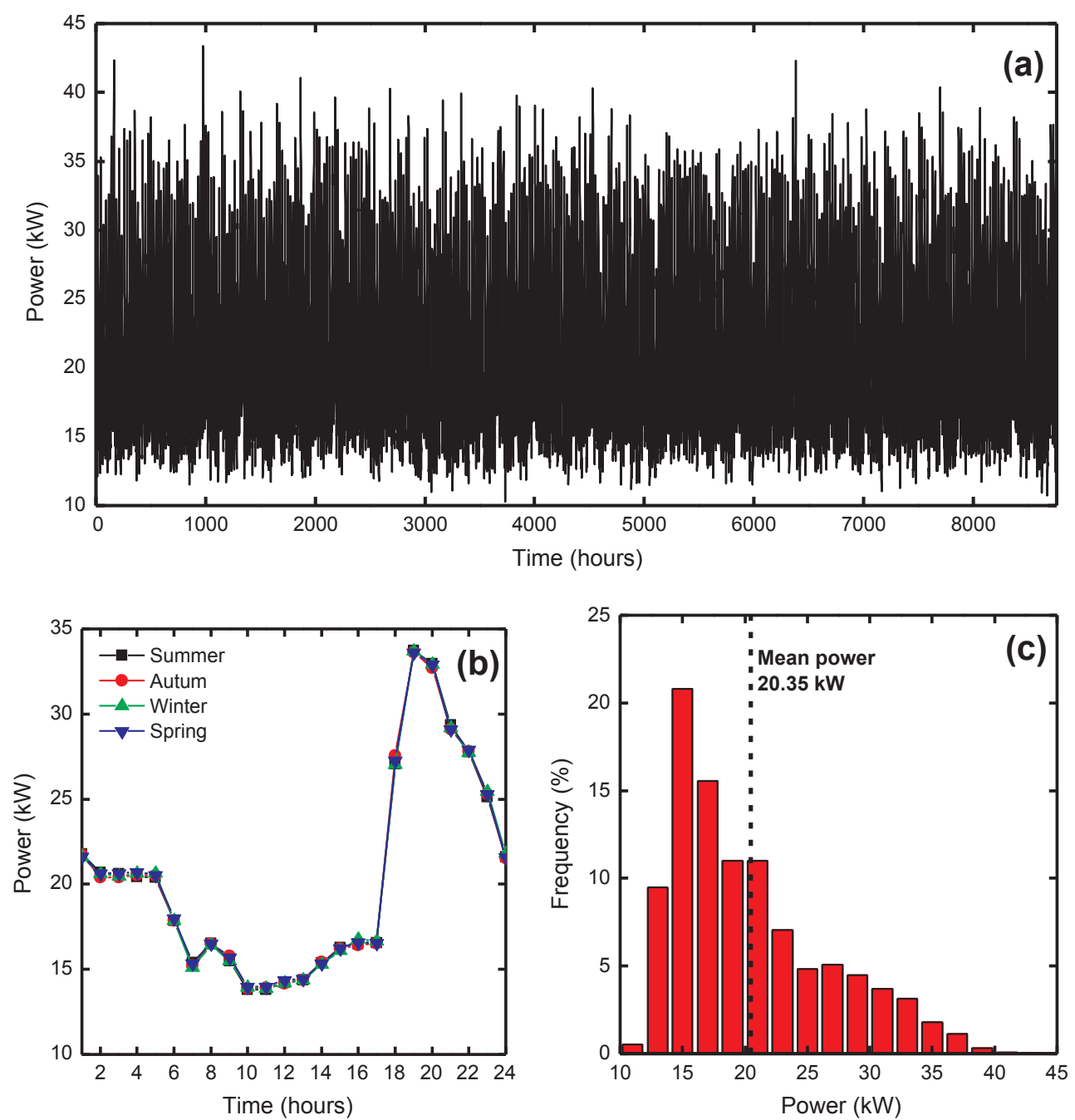

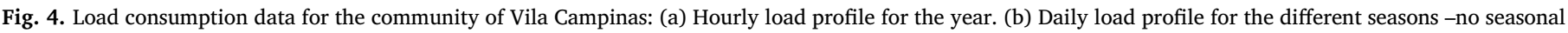
variation was considered-. (c) Histogram of power consumption.

compared to summer and autumn. The mean wind speed is $2.54 \mathrm{~m} / \mathrm{s}$ at $50 \mathrm{~m}$ height as observed in Fig. 5(c). The hourly global solar irradiance for the year is presented in Fig. 6(a). The solar resource is fairly constant all year long with a mean value of $4.6 \mathrm{kWh} / \mathrm{m}^{2} /$ day. During summer and autumn, the solar irradiance is lower since this period corresponds to the rainy season with a higher presence of clouds (see Fig. 6(b)). The mean solar irradiance when the sun is above de horizon is $0.38 \mathrm{~kW} / \mathrm{m}^{2}$ as observed in Fig. 6(c).

\section{Results and discussion}

\subsection{Deterministic optimization}

In this section, the HPS is dimensioned disregarding the uncertainties. Table 1 presents the range of variation of the optimization variables. The upper and lower limits of the variables related to the number of components $\left(N_{j, \text { min }}, N_{j, \text { max }}\right)$ were defined in the pre-dimensioning stage (see Section 2 and Fig. 2). For each system component, there are four possible models $\left(T_{j}\right)$ which were selected based on the availability of equipment in the Brazilian domestic market. There are two dispatch strategies available (Ec), the Load Following (LF) and Cycle Charging (CC). The total number of combinations results equal to $1.43 \times 10^{13}$, constituting a vast search space. The restrictions of the problem were set as follows: $L P S P_{a d m}=5 \%, f_{\text {ren, } \min }=0 \%$, $f_{\text {exess }, a d m}=100 \%, F_{d g, a d m}=\inf \left(\mathrm{L} /\right.$ year), $E M C O_{2, a d m}=\inf (\mathrm{t} /$ year $)$ and
$N P V_{C, a d m}=\inf (\$ /$ year $)$.

The technical characteristics of the adopted components and the parameters needed for the simulations are shown in Table 2.

Table 3 shows the costs used for the economic analysis. The initial capital cost equations are correlations derived from data provided by local suppliers. The replacement cost and the operation and maintenance cost derive from values reported in the specialized literature [50-52]. Other data used for the economic analysis are the real interest rate of $4.8 \%$ per year and the cost of diesel fuel of 0.734 \$ L [53].

Table 4 presents the emission factors employed in the life cycle emission analysis, these values derive from $[54,55]$.

Finally, Table 5 reports the configuration of the NSGA-II algorithm adopted. This configuration gives the best performance of the NSGA-II algorithm for the studied problem.

The algorithm implemented in Matlab ${ }^{\circledR}$ employed, on average, 65 minutes using a computer equipped with Windows 7, 64 Bits, an AMD $\mathrm{FX}^{\mathrm{TM}}-8150$ 8-core processor $3 \mathrm{GHz}$ and $16 \mathrm{~GB}$ of RAM.

Fig. 7 presents the deterministic Pareto front (PF) of the last generation (200) for the multi-objective optimization problem. The LPS is outlined in the vertical left axis and the curves show different values of $N P V_{C}$ needed to obtain the design with the corresponding LPS. Also the vertical right axis represents the LPSP.

Three solutions of interest from the PF are shown in black filled marker. The uppermost left black marker in Fig. 7 (Sol 1), corresponds to the solution with lowest cost and highest energy not supplied (lowest 

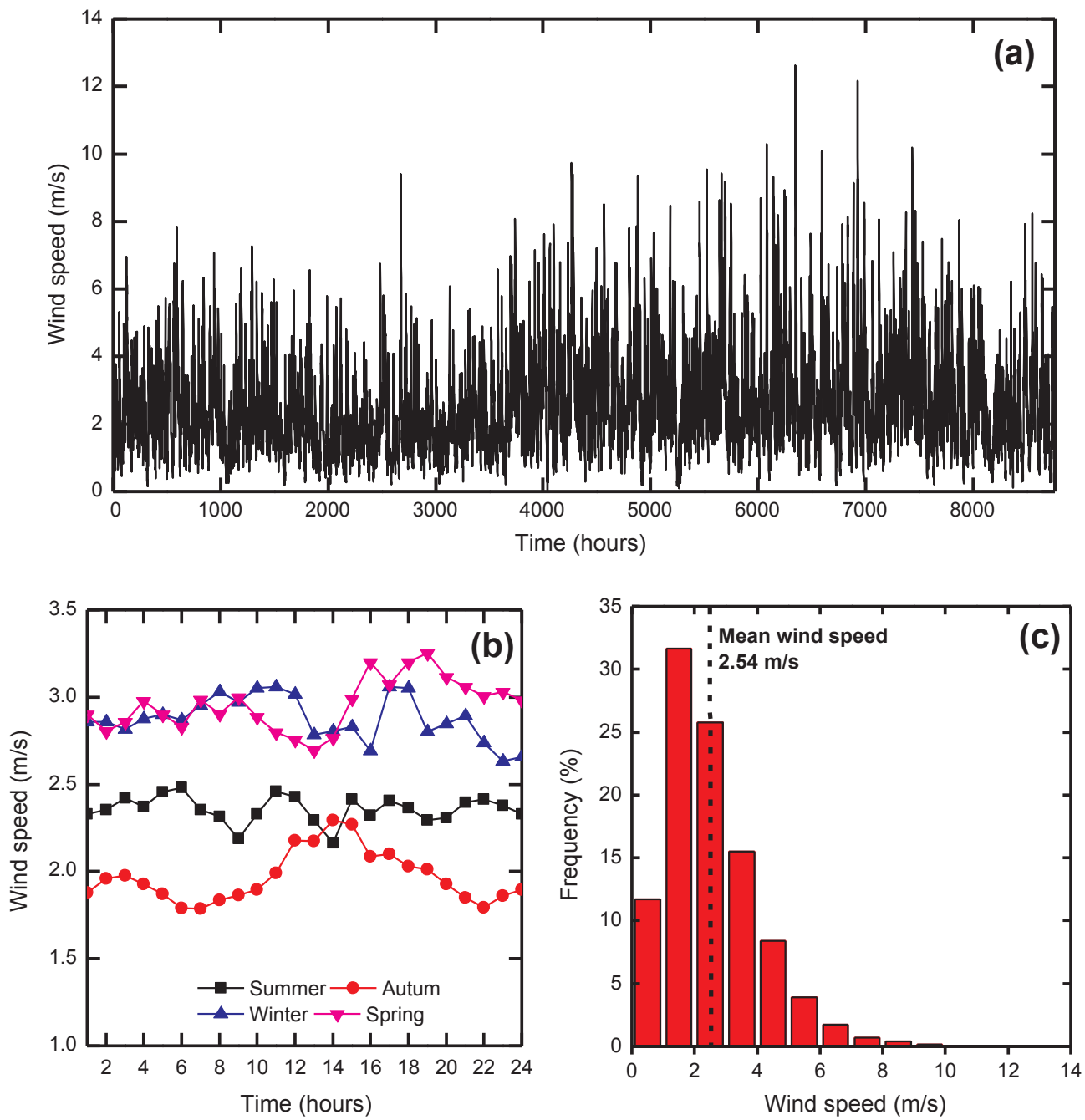

Fig. 5. Wind speed resource in Vila Campinas: (a) Hourly wind speed profile for the year. (b) Daily wind speed profile for the different seasons. (c) Histogram of wind speed.

reliability), whereas the downmost right black marker in Fig. 7 (Sol 3) is the highest cost solution and lowest energy not supplied (highest reliability). The PF has two discontinuities which derive from the discrete characteristic of the optimization variables. It is possible to identify a trade-off solution which is located in the knee of the curve, Sol 2. In Table 6 are presented the characteristics of the three solutions of interest.

None of the solutions include wind turbines, showing that the wind potential is low, making energy generation not viable in this region. On the other hand, the PV contribution results are high in all the solutions. The high values of Performance Ratio (PR), above 76\%, show that the PV plant is efficient and reliable. This, coupled with the low cost of the $\mathrm{PV}$ panels makes the photovoltaic generation an attractive alternative. Also, all the solutions include at least one diesel generator in its configuration. The HPS must rely on a backup generation source to meet the restriction of maximum energy not supplied (LPSP ${ }_{a d m}$ of $5 \%$ ).

The battery bank resulted the same for the three solutions, both in capacity and in the model of the component. This configuration allows the systems to have over 29 hours of autonomy. Also, the battery lifespan is comparable for all the solutions, meaning that the batteries undergo similar operating conditions.

The algorithm selected the Load Following (LF) dispatch strategy for the three solutions. This strategy is suitable for power systems with a large share of renewable generation, such as the solutions in Table 6 for which the renewable energy fraction (RF) exceeds $80 \%$.
The reliability indicators DIC (Interruption Duration per Consumer Unit) and FIC (Interruption Frequency per Consumer Unit) are used to gauge the quality of the electric-power services to individual consumer units. The ANEEL, Brazilian Electricity Regulatory Agency, continuously monitors these indicators in the different regions of Brazil. It establishes that for rural consumers in the region of Vila Campinas the value of DIC is 100 hours, while the FIC is 92 interruptions per year [56]. Considering these values, the only configuration that fulfills these reliability standards is Sol 3 .

The cost of improving the reliability from $5 \%$ to $0 \%$ energy not supplied equals the difference of $N P V_{C}$ between solutions 1 and 3, i.e. \$ $782278.25-\$ 715096.44=\$ 67181.81$, meaning an increase in the $N P V_{C}$ of $9.39 \%$.

\subsection{Sensitivity of deterministic solutions}

The HPS configurations obtained in Section 4.1 are clearly determined once the input conditions are specified. Since the simulation algorithm is deterministic, given the same input information the results will always be the same. However, in real systems there are uncertainties inherent to the input variables. When these uncertainties are considered, the results must be expressed in a non-deterministic fashion, either probabilistically or as ranges of possible values.

In this section it is assessed the influence of the uncertainties in the input variables over the deterministic solutions obtained in Section 4.1 

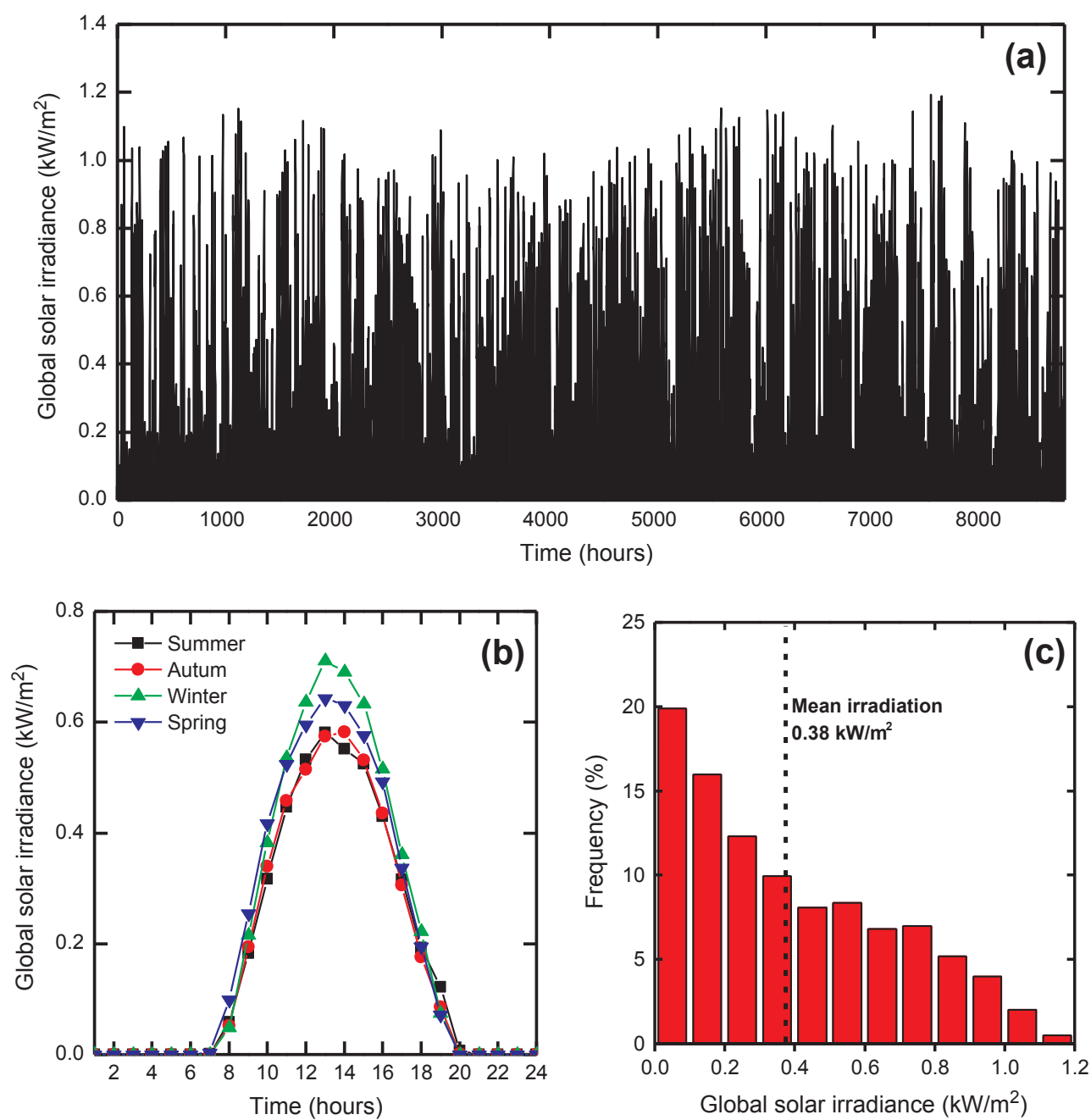

Fig. 6. Global solar irradiance in Vila Campinas: (a) Hourly solar irradiance profile for the year. (b) Daily solar irradiance profile for the different seasons. (c) Histogram of solar irradiance during the day.

Table 1

Range of the variables for the HPS optimization problem.

\begin{tabular}{|c|c|}
\hline Variable & Vila campinas \\
\hline$\left[N_{w t, \min ,} N_{w t, \max }\right]$ & {$[0,250]$} \\
\hline$T_{w t}$ & $\{1 ; 6 ; 7 ; 10\} \mathrm{kW}$ \\
\hline$\left[N_{p v, \min }, N_{p v, \max }\right]$ & {$[0,2400]$} \\
\hline$T_{p v}$ & $\{0.064 ; 0.08 ; 0.11 ; 0.12\} \mathrm{kWp}$ \\
\hline$\left[N_{d g, \min ,} N_{d g, \max }\right]$ & {$[0,16]$} \\
\hline$T_{d g}$ & $\{2.8 ; 10 ; 16 ; 48\} \mathrm{kW}$ \\
\hline$\left[N_{b t, p, \min ,} N_{b t, p, \max }\right]$ & {$[0,30]$} \\
\hline$T_{b t}$ & $\{198 ; 226 ; 1192 ; 3565\} \mathrm{kWh}$ \\
\hline$\left[N_{\text {conv, min, }}, N_{\text {conv, } \max }\right]$ & {$[0,10]$} \\
\hline$T_{\text {conv }}$ & $\{5 ; 7 ; 17 ; 50\} \mathrm{kW}$ \\
\hline$E c$ & $\{\mathrm{LF} ; \mathrm{CC}\}$ \\
\hline $\mathrm{N}^{\circ}$ of possible combinations & $1.43 \times 10^{13}$ \\
\hline
\end{tabular}

for the case study of Vila Campinas.

The approach used consists in iteratively simulate the HPS introducing uncertainties in the input variables wind speed, solar irradiance, temperature, load demand and components' failure rate. These are probabilistically generated according to the method presented in Section 2.2. It was determined that a number of 1000 samples suffice to reach the desired level of convergence, based on the speed of convergence of the performance indicators $N P V_{C}$ and $L P S$. Details about the parameters used by the sampling method can be found in Table 7 .

The probabilistic simulation was performed over the three solutions of interest studied in Section 4.1 and presented in Table 6. Simulating each configuration probabilistically 1000 times took an average of 10 minutes using the aforementioned hardware. The probability density curves presented in Fig. 8(a) and (b) show a clear representation of the variability of the solutions with respect to the $N P V_{C}$ and the LPS.

Solution 1 incorporates only one diesel generator (see Table 6), therefore this HPS configuration is more sensitive to uncertainties in the operating conditions showing greater dispersion of the LPS in Fig. 8(b). On the other hand, the operating cost of the system is greatly influenced by the amount of fuel consumed by the backup generator, thus Solution 1 presents a lower dispersion of the $N P V_{C}$ as observed in Fig. 8(a). The opposite occurs with Solution 3 that incorporates three diesel generators (see Table 6). This is a more robust configuration in the presence of uncertainties, presenting lower dispersion of the LPS in Fig. 8(b), but higher dispersion of the $N P V_{C}$ in Fig. 8(a). Solution 2 presents a behavior somewhere in the middle of Solutions 1 and 3.

The results indicate that the deterministic solutions of the PF present variability in the presence of uncertainties related to the input variables. Fig. 9 shows how the mean of the deterministic solutions simulated probabilistically, $\mu(\mathrm{Sol})^{\text {Pareto (det.) }}$, move away from the deterministic PF, Sol(det.), indicating the necessity to incorporate an uncertainty quantification method in the optimization process to obtain robust solutions with respect to the objectives considered. 
Table 2

Technical data of the HPS components used in the simulations.

\begin{tabular}{|c|c|c|}
\hline \multirow[t]{6}{*}{ PV panels } & Technology & poli-Si \\
\hline & Rated power $\left(Y_{p v}\right)$ & $0.064,0.08,0.11,0.12 \mathrm{kWp}$ \\
\hline & $\begin{array}{l}\text { Temperature coefficient of } \\
\text { power }\left(\alpha_{p}\right)\end{array}$ & $-0.005 \% /{ }^{\circ} \mathrm{C}$ \\
\hline & Cell temperature at STC $\left(T_{c, S T C}\right)$ & $25^{\circ} \mathrm{C}$ \\
\hline & Power reduction factor $\left(f_{p v}\right)$ & $0.842 \%$ \\
\hline & Lifetime & 25 years \\
\hline \multirow[t]{6}{*}{ WT } & Technology & 3 blade horizontal axis \\
\hline & Rated power $\left(P_{w t r}\right)$ & $1,6,7,10 \mathrm{~kW}$ \\
\hline & Hub height & $20,20,17.5,20 \mathrm{~m}$ \\
\hline & Power law coefficient & 0.143 \\
\hline & Surface roughness & $0.01 \mathrm{~m}$ \\
\hline & Lifetime & 20 years \\
\hline \multirow[t]{6}{*}{ DG } & Technology & $\begin{array}{l}\text { Diesel IC coupled with an electric } \\
\text { generator }\end{array}$ \\
\hline & Rated power $\left(P_{d g r}\right)$ & $2.8,10,16,48 \mathrm{~kW}$ \\
\hline & $\begin{array}{l}\text { Fuel curve intercept coefficient } \\
\left(F_{0}\right)\end{array}$ & $0.084 \mathrm{~L} / \mathrm{h} / \mathrm{kW}_{\text {rated }}$ \\
\hline & Slope coefficient $\left(F_{1}\right)$ & $0.246 \mathrm{~L} / \mathrm{h} / \mathrm{kW}$ \\
\hline & Lifetime & $10000 \mathrm{~h}$ \\
\hline & Diesel fuel LHV & $43.2 \mathrm{MJ} / \mathrm{kg}$ \\
\hline \multirow[t]{6}{*}{ BT } & Technology & Lead-acid battery \\
\hline & Nominal capacity & $200,225,1000,3000 \mathrm{Ah}$ \\
\hline & Nominal voltage & $12,6,2,2 \mathrm{~V}$ \\
\hline & Roundtrip efficiency & $80,85,86,86 \%$ \\
\hline & Minimum State of Charge & $40,30,30,30 \%$ \\
\hline & Lifetime throughput & $917,845,3438,10,196 \mathrm{kWh}$ \\
\hline \multirow[t]{3}{*}{ CONV } & Rated power $\left(P_{d c, \text { rated }}\right)$ & $5,7,17,50 \mathrm{~kW}$ \\
\hline & $\begin{array}{l}\text { Average conversion efficiency } \\
\left(\eta_{\text {conv }}\right)\end{array}$ & $90 \%$ \\
\hline & Lifetime & 10 years \\
\hline
\end{tabular}

\subsection{Optimization under uncertainty}

In this section the proposed probabilistic optimization approach which incorporates the uncertainties within the optimization process is implemented. The results are compared with the deterministic HPS configurations obtained in Section 4.1 for the study case.

The uncertainties considered and the sampling methods used are the same as those adopted in the previous Section 4.2, with the parameters shown in Table 7. The algorithm was configured with a population size of 100 individuals, a maximum number of generations of 200 and a number of samples of 50. With this setting, the probabilistic multi-objective optimization algorithm needs to evaluate the objective function $1 \times 10^{6}$ times in each simulation. Using the same hardware as with the previous simulations, and implementing parallel computing, the mean time for simulation resulted in $15 \mathrm{~h}$.

The probabilistic simulation used as a starting point the last generation obtained by the deterministic algorithm, that is, the individuals of the deterministic PF constitute the first generation of the probabilistic algorithm. The idea behind this approach is to accelerate the convergence of the probabilistic algorithm and to allow a later comparison with the solutions of the deterministic algorithm.

Fig. 10 shows the probabilistic PF obtained for the optimization problem $\min f_{m}\left(N P V_{C}, L P S\right)$ for the case study of Vila Campinas. It also
Table 4

Emission factors used in the life cycle emissions analysis.

\begin{tabular}{lllll}
\hline Component & \multicolumn{2}{l}{ Indirect emission factor } & \multicolumn{2}{c}{ Direct emission factor ${ }^{\mathrm{a}}$} \\
\hline $\mathrm{PV}$ & 0.059 & $\mathrm{kgCO}_{2}-\mathrm{eq} / \mathrm{kWh}$ & - & \\
$\mathrm{WT}$ & 0.02 & $\mathrm{kgCO}_{2}-\mathrm{eq} / \mathrm{kWh}$ & - & \\
$\mathrm{CONV}$ & 42.835 & $\mathrm{kgCO}_{2}-\mathrm{eq} / \mathrm{kW}$ & - & \\
$\mathrm{BT}$ & 59.42 & $\mathrm{kgCO}_{2}-\mathrm{eq} / \mathrm{kWh}$ & - & \\
DG & 454.293 & $\mathrm{kgCO}_{2}-\mathrm{eq} / \mathrm{kW}$ & 2.64 & $\mathrm{kgCO}_{2}-\mathrm{eq} / \mathrm{L}$ \\
Diesel fuel & 0.530 & $\mathrm{kgCO}_{2}-\mathrm{eq} / \mathrm{L}$ & - & \\
\hline
\end{tabular}

${ }^{\text {a }}$ Emissions generated during the manufacturing, transportation and disposal stages.

${ }^{\mathrm{b}}$ Emissions generated during the operation stage.

Table 5

Parameters of the NSGA-II algorithm used in the HPS optimization problem.

\begin{tabular}{lll}
\hline Operator & Method & Parameter \\
\hline Population size & - & popSize $=100$ \\
Restriction handle method & Dominance based method & niching $=$ yes \\
Selection method & Binary tournament & Tournament size $=2$ \\
Reinsertion strategy & "N $N_{\text {best }}$ " individuals & $N_{\text {best }}=$ popSize \\
Stopping criteria & Maximum number of & maxGen $=200$ \\
& generations & \\
Recombination operator & BLX- $\alpha$ & 0.5 \\
Recombination probability & - & 0.9 \\
Mutation operator & Non-uniform & 5 \\
Mutation probability & - & $1 / \mathrm{n}$
\end{tabular}

depicts the deterministic PF, obtained in Section 4.1, and the mean probabilistic solutions, $\mu(\mathrm{Sol})^{\text {Pareto (det.) }}$, computed in Section 4.2.

The probabilistic PF lays to the right of the deterministic PF, indicating that a robust configuration of the HPS with the same level of reliability as in the deterministic scenario implies a higher $N P V_{C}$. All the solutions of the probabilistic $\mathrm{PF}$ are within the feasible region, limited by $L P S_{a d m}=5 \%$ (dashed horizontal line in Fig. 10). This is not the case for the mean probabilistic solution located in the upper left corner of Fig. 10 which does not satisfy this restriction. Including the uncertainties within the optimization process ensures that all the configurations of the probabilistic PF represent feasible and robust solutions.

Table 8 presents the characteristics of the three solutions of interest obtained with the deterministic and the probabilistic algorithms. This table can be used to choose among solutions. The solutions are tagged in Fig. 10 and correspond to Solution 1 (minimum $N P V_{C}$ and maximum $L P S$ ), Solution 2 (trade-off solution) and Solution 3 (maximum $N P V_{C}$ and minimum $L P S$ ).

The probabilistic algorithm increases the use of the generator and reduces the battery bank capacity with respect to the deterministic algorithm. This is observed in Solutions 1 and 2 where the configurations obtained by the probabilistic algorithm do not include a battery bank. The generator is a dispatchable source of generation that allows the HPS more flexibility to offset the variations in the demand and the renewable resources. Thus, when the uncertainties are included in the optimization process, the generator becomes a more attractive generation option, for the case study scenario.

Solution 3 represents the configuration with the lowest energy not

Table 3

Costs used in the economic analysis.

\begin{tabular}{|c|c|c|c|}
\hline Component & Initial capital (\$) & Replacement (\$) & Operation and maintenance \\
\hline PV & $C_{i c a p, p v}=10.06\left(P_{p v r}\right)^{-0.39}$ & $C_{r e p, p v}=C_{\text {icap }, p v} \times 0.75$ & $C_{o \& m, p v}=C_{\text {icap }, p v} \times 0.001(\$ /$ year $)$ \\
\hline WT & $C_{i c a p, w t}=4064.97\left(P_{w t r}\right)^{-0.1656}$ & $C_{r e p, w t}=C_{\text {icap }, w t}-501.44 \times H_{\text {torre }}$ & $C_{o \& m, w t}=C_{i c a p, w t} \times 0.002(\$ /$ year $)$ \\
\hline CONV & $C_{\text {icap, conv }}=617.49\left(P_{\text {convr }}\right)^{0.224}$ & $C_{\text {rep,conv }}=C_{\text {icap,conv }}$ & $C_{o \& m, \text { conv }}=0(\$ /$ year $)$ \\
\hline BT & $C_{i c a p, b t}=148.74\left(P_{b t r}\right)^{-0.275}$ & $C_{r e p, b t}=C_{i c a p, b t}$ & $C_{o \& m, b t}=10(\$ /$ year $)$ \\
\hline DG & $C_{i c a p, d g}=325.39\left(P_{d g r}\right)^{-0.0051}$ & $C_{\text {rep }, d g}=C_{i c a p, d g}$ & $C_{o \& m, d g}=0.25(\$ / \mathrm{h})$ \\
\hline
\end{tabular}




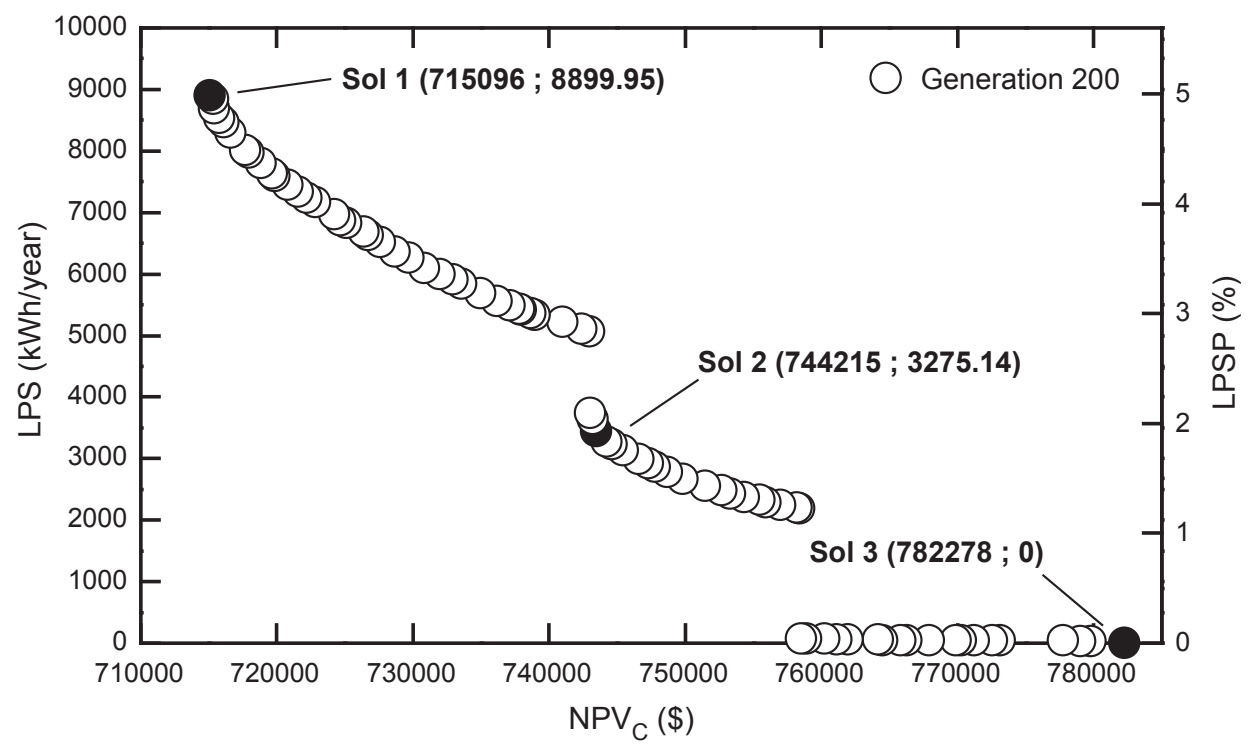

Fig. 7. Deterministic PF and solutions of interest for the HPS dimensioning problem.

Table 6

Characteristics of 3 solutions of interest obtained with the deterministic multi-objective optimization algorithm.

\begin{tabular}{|c|c|c|c|}
\hline & Sol 1 & Sol 2 & Sol 3 \\
\hline $\mathrm{WT}(\mathrm{kW})$ & 0.00 & 0.00 & 0.00 \\
\hline $\mathrm{PV}(\mathrm{kW})$ & $131.64(1097 \times 0.12 \mathrm{~kW})$ & $139.44(1162 \times 0.12 \mathrm{~kW})$ & $150.00(1250 \times 0.12 \mathrm{~kW})$ \\
\hline DG $(\mathrm{kW})$ & $16.00(1 \times 16 \mathrm{~kW})$ & $20.00(2 \times 10 \mathrm{~kW})$ & $48.00(3 \times 16 \mathrm{~kW})$ \\
\hline \multirow[t]{2}{*}{ BT (kWh) } & 855.60 & 855.60 & 855.60 \\
\hline & $(1 \times 120$ bat., $3565 \mathrm{Ah}, 2 \mathrm{~V})$ & $(1 \times 120$ bat., $3565 \mathrm{Ah}, 2 \mathrm{~V})$ & $(1 \times 120$ bat., $3565 \mathrm{Ah}, 2 \mathrm{~V})$ \\
\hline CONV (kW) & $35.00(7 \times 5 \mathrm{~kW})$ & $35.00(7 \times 5 \mathrm{~kW})$ & $35.00(7 \times 5 \mathrm{~kW})$ \\
\hline Dispatch strategy & $\mathrm{LF}$ & $\mathrm{LF}$ & $\mathrm{LF}$ \\
\hline Load consumption (kWh/year) & 178253.48 & 178253.48 & 178253.48 \\
\hline LPSP (\%) & 4.99 & 1.84 & 0.00 \\
\hline DIC (h/year) & 1481.00 & 831.00 & 0.00 \\
\hline FIC (int/year) & 188.00 & 204.00 & 0.00 \\
\hline EXE $(\%)$ & 0.64 & 1.88 & 4.48 \\
\hline $\mathrm{RF}(\%)$ & 83.75 & 84.61 & 86.42 \\
\hline PR (PV performance ratio) & 0.76 & 0.76 & 0.76 \\
\hline BT life (years) & 11.90 & 11.25 & 10.53 \\
\hline DG hours of operation (h/year) & 2450.00 & 2139.00 & 1781.00 \\
\hline Fuel consumption (L/year) & 11283.56 & 11100.42 & 11142.73 \\
\hline Emissions $\left(\mathrm{tCO}_{2-\mathrm{eq}} /\right.$ year $)$ & 29.80 & 29.32 & 29.44 \\
\hline Initial capital cost $(\$)$ & 486001.34 & 502120.52 & 525408.80 \\
\hline Cost of operation ( $\$ /$ year) & 18013.89 & 19036.02 & 20197.81 \\
\hline LCOE $(\$ / \mathrm{kWh})$ & 0.332 & 0.334 & 0.345 \\
\hline $\mathrm{NPV}_{\mathrm{C}}(\$)$ & 715096.44 & 744214.71 & 782278.25 \\
\hline
\end{tabular}

Table 7

Parameters of the sampling method used to generate probabilistic scenarios.

\begin{tabular}{llll}
\hline & Value & Unit & Reference \\
\hline $\begin{array}{l}\text { Standard deviation of annual mean } \\
\quad \text { wind speed }\end{array}$ & 0.15 & $\mathrm{~m} / \mathrm{s}$ & {$[57]$} \\
$\begin{array}{l}\text { Standard deviation of annual mean } \\
\text { solar insolation }\end{array}$ & 1.15 & $\begin{array}{l}\mathrm{kWh} / \mathrm{m}^{2} / \\
\mathrm{day}\end{array}$ & {$[58]$} \\
$\begin{array}{l}\text { Standard deviation of annual mean } \\
\text { ambient temperature }\end{array}$ & 5.00 & ${ }^{\circ} \mathrm{C}$ & {$[59]$} \\
$\begin{array}{l}\text { Standard deviation of annual load } \\
\text { consumption }\end{array}$ & 48.84 & $\mathrm{kWh} /$ day & Assumed by \\
MTBF WT & 1920 & $\mathrm{~h}$ & author \\
MTTR WT & 80 & $\mathrm{~h}$ & \\
MTBF PV panel & 2190 & $\mathrm{~h}$ & \\
MTTR PV panel & 80 & $\mathrm{~h}$ & \\
MTBF DG & 950 & $\mathrm{~h}$ & \\
MTTR DG & 50 & $\mathrm{~h}$ & \\
MTBF CONV & 87,600 & $\mathrm{~h}$ & \\
MTTR CONV & 80 & $\mathrm{~h}$ & \\
\hline
\end{tabular}

MTBF: Mean time between failures; MTTR: Mean time to repair. supplied (LPS $=0 \%)$. To attain this level of reliability in the presence of uncertainties is necessary to add more generation capacity, as observed in the last two columns of Table 8. The probabilistic Solution 3 increases $30 \%$ the diesel generation (from $48 \mathrm{~kW}$ to $64 \mathrm{~kW}$ ) and $19.3 \%$ the PV generation (from $150 \mathrm{~kW}$ to $178.92 \mathrm{~kW}$ ) with respect to the deterministic Solution 3 . The battery bank capacity remains the same.

To illustrate how the uncertainties affect the operation of the HPS configurations it is presented the hourly simulation of the system operation over a period of 10 days. Fig. 11 corresponds to the simulation of Solution 3 obtained by the deterministic algorithm, and Fig. 12 corresponds to Solution 3 obtained by the probabilistic algorithm (see Table 8).

The time period presented in the figures has a sequence of 6 days of low solar radiation and, therefore, the PV system power generation (Ppv) is low. The battery bank reaches its minimum state of charge of $30 \%$ (SOC) failing to supply the load demand (Pload). Thus, it is necessary to start the backup diesel generation (Pdg) to supply the energy deficit. When the solar radiation increases in the next 4 days, the PV system generates enough energy to supply the load and charge the 

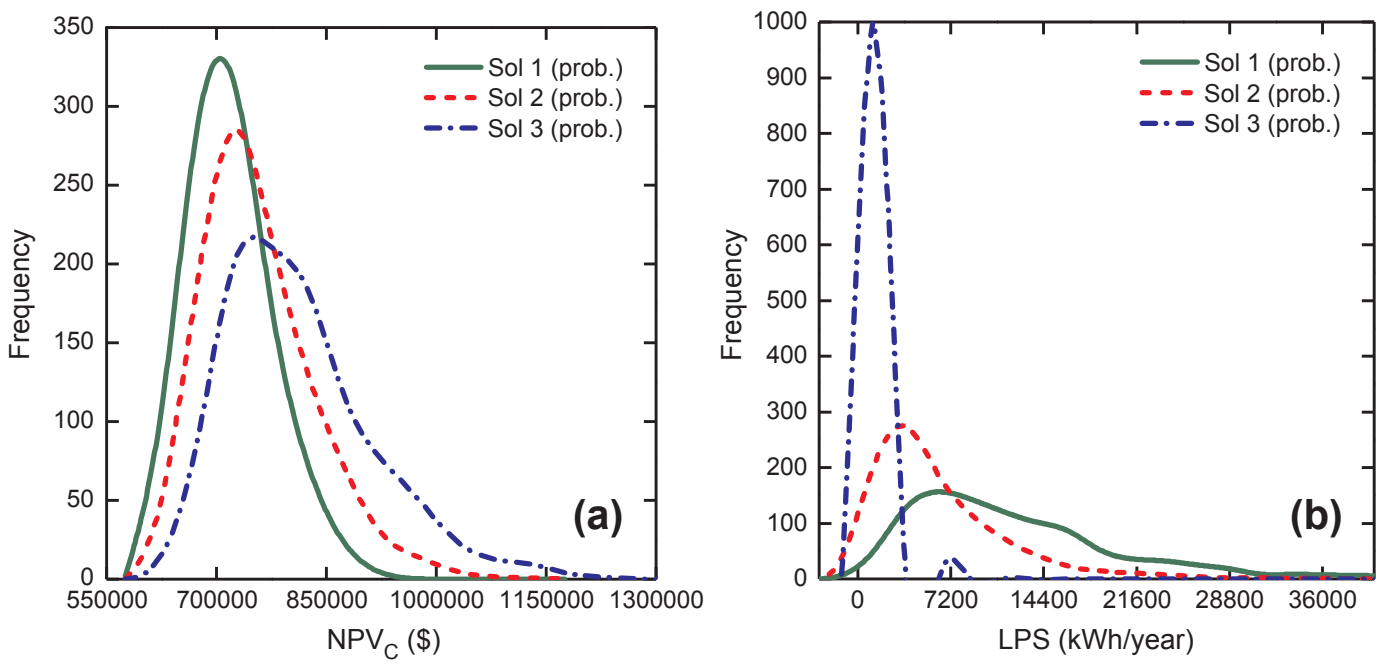

Fig. 8. Probability density functions of (a) NPVc and (b) LPS derived from the probabilistic simulation of the deterministic solutions.

batteries to its maximum state of charge. In Fig. 11, the energy balance between the demand and the generation is completely deterministic for each hour of operation of the HPS. On the other hand, in Fig. 12, the power for each hour is represented by a mean value and a band of variation due to the uncertainties introduced. Dimensioning the HPS based on the mean values leads to under-dimensioned systems that would not be able to satisfy the demand properly, thus the necessity of considering the uncertainties within the optimization process.

When the computational resources or the time are limited, is recommended to apply the probabilistic simulation technique to the deterministic Pareto solutions as a prior analysis. This approach, which represents only $10 \%$ of the computational time spent by the probabilistic optimization, can assess the influence of the uncertainties in the deterministic solutions. If the mean of the deterministic solutions assessed under uncertainty exceeds the constraints imposed by the user, it is possible to run the probabilistic optimization algorithm ensuring that the solutions are robust and within the feasible region of the search space.

\section{Conclusions}

In this work, we tackle the problem of dimensioning a renewable based Hybrid Power System for the supply of electricity to isolated rural communities. Previous research in the field has almost exclusively made use of deterministic optimization algorithms for sizing the system. When uncertainties are considered, this is done through postoptimization sensitivity analysis. The sources of uncertainty studied include the renewable resources availability, the load demand and to a lesser extent the components' failure rate. However, no previously work has considered all of these uncertainties simultaneously. We argue that it is necessary to design robust generation systems to guarantee the reliable electricity supply of rural communities. For this, all uncertainties related to the input variables must be considered in the optimization process.

To solve this problem, it is proposed a probabilistic simulationbased optimization approach for the optimal design an autonomous Hybrid Power System taking into account the uncertainties in the renewable resources availability, the load demand and the unavailability of the components subjected to failure.

The proposed method was implemented as a Matlab ${ }^{\circledR}$ toolbox. It integrates three modules that interact in the search of the best solution. The Optimization Module implements a multi-objective Genetic Algorithm, modified to incorporate the uncertainties in the optimization process. The Uncertainty Module generates the uncertainty scenarios through the use of probability distribution functions. The Simulation Module simulates the system operation under the real operating conditions defined by the uncertainty scenarios. The outputs of the Simulation Module are the objective functions and a series of performance indices used to guide the search process.

The method was applied for dimensioning a solar-wind-diesel-

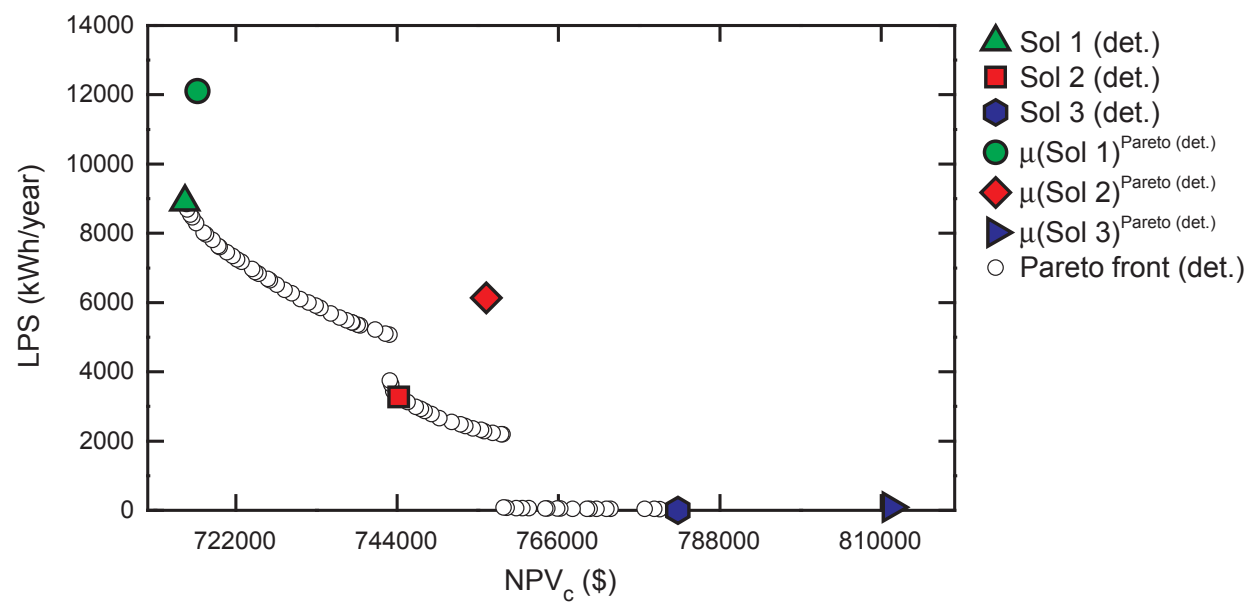

Fig. 9. Plot showing how the deterministic solutions assessed probabilistically move away from the deterministic Pareto front. 


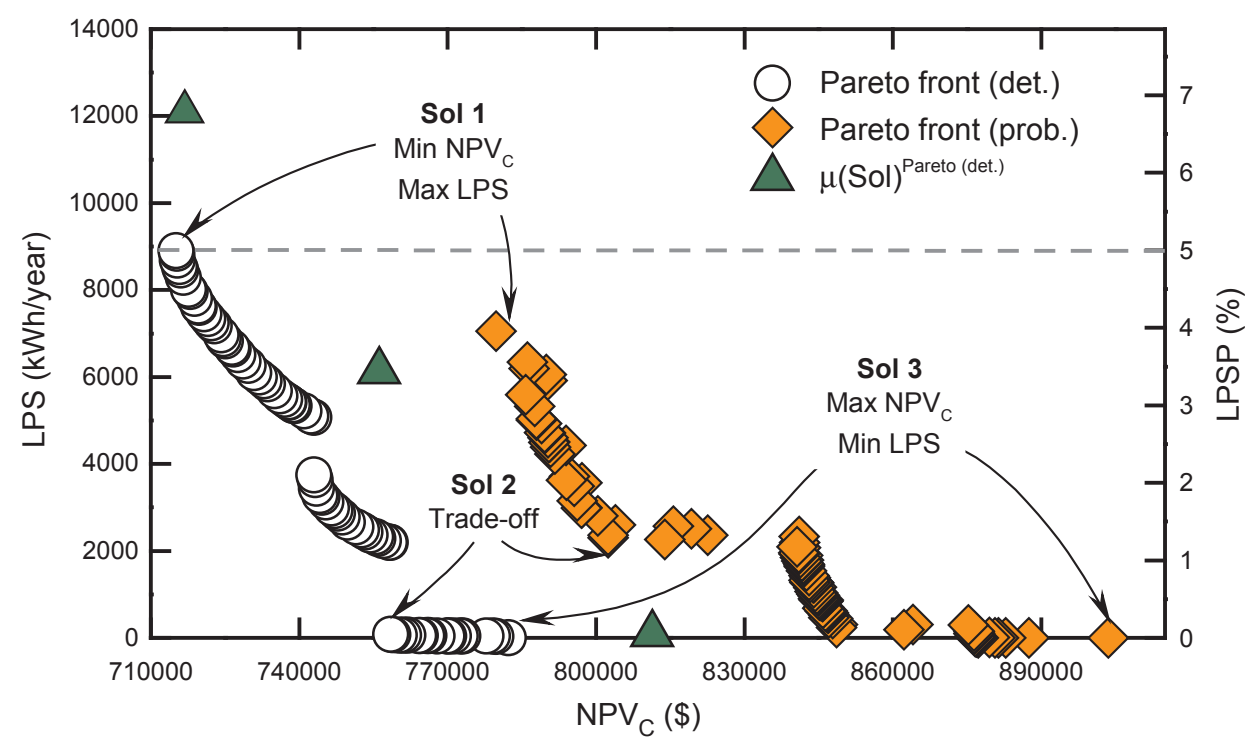

Fig. 10. Comparison between deterministic Pareto front (white circles), mean probabilistic solutions (green triangles) and probabilistic Pareto front (orange diamonds).

Table 8

Characteristics of three solutions of interest obtained with the deterministic (det.) and the probabilistic (prob.) multi-objective optimization algorithms.

\begin{tabular}{|c|c|c|c|c|c|c|}
\hline & \multicolumn{2}{|l|}{$\begin{array}{l}\text { Sol } 1 \\
\text { Min. } \mathrm{NPV}_{\mathrm{C}} \text { and Max. LPS }\end{array}$} & \multicolumn{2}{|l|}{$\begin{array}{l}\text { Sol } 2 \\
\text { Trade-off }\end{array}$} & \multicolumn{2}{|l|}{$\begin{array}{l}\text { Sol } 3 \\
\text { Max. } \mathrm{NPV}_{\mathrm{C}} \text { and Min. LPS }\end{array}$} \\
\hline & (det.) & (prob.) & (det.) & (prob.) & (det.) & (prob.) \\
\hline $\mathrm{PV}(\mathrm{kW})$ & $131.64(1097 \times 0.12 \mathrm{~kW})$ & $\begin{array}{l}51.00 \\
(425 \times 0.12 \mathrm{~kW})\end{array}$ & $\begin{array}{l}138.12 \\
(1151 \times 0.12 \mathrm{~kW})\end{array}$ & $\begin{array}{l}52.08 \\
(434 \times 0.12 \mathrm{~kW})\end{array}$ & $150.00(1250 \times 0.12 \mathrm{~kW})$ & $178.92(1491 \times 0.12 \mathrm{~kW})$ \\
\hline${ }^{\mathrm{DG}} \underset{(\mathrm{kW})}{ }$ & $\begin{array}{l}16.00 \\
(1 \times 16 \mathrm{~kW})\end{array}$ & $\begin{array}{l}32.00 \\
(2 \times 16 \mathrm{~kW})\end{array}$ & $\begin{array}{l}32.00 \\
(2 \times 16 \mathrm{~kW})\end{array}$ & $\begin{array}{l}32.00 \\
(2 \times 16 \mathrm{~kW})\end{array}$ & $\begin{array}{l}48.00 \\
(3 \times 16 \mathrm{~kW})\end{array}$ & $\begin{array}{l}64.00 \\
(4 \times 16 \mathrm{~kW})\end{array}$ \\
\hline CONV $(\mathrm{kW})$ & $\begin{array}{l}35.00 \\
(7 \times 5 \mathrm{~kW})\end{array}$ & $\begin{array}{l}20.00 \\
(4 \times 5 \mathrm{~kW})\end{array}$ & $\begin{array}{l}35.00 \\
(7 \times 5 \mathrm{~kW})\end{array}$ & $\begin{array}{l}25.00 \\
(5 \times 5 \mathrm{~kW})\end{array}$ & $\begin{array}{l}35.00 \\
(7 \times 5 \mathrm{~kW})\end{array}$ & $\begin{array}{l}35.00 \\
(7 \times 5 \mathrm{~kW})\end{array}$ \\
\hline Dispatch strategy & LF & LF & LF & LF & LF & LF \\
\hline $\begin{array}{l}\text { LPSP } \\
\text { (\%) }\end{array}$ & 4.99 & 4.07 & 0.04 & 1.30 & 0.00 & 0.00 \\
\hline $\mathrm{NPV}_{\mathrm{C}}$ (US\$) & 715096.44 & 779774.00 & 758525.67 & 813906.00 & 782278.25 & 903571.00 \\
\hline
\end{tabular}

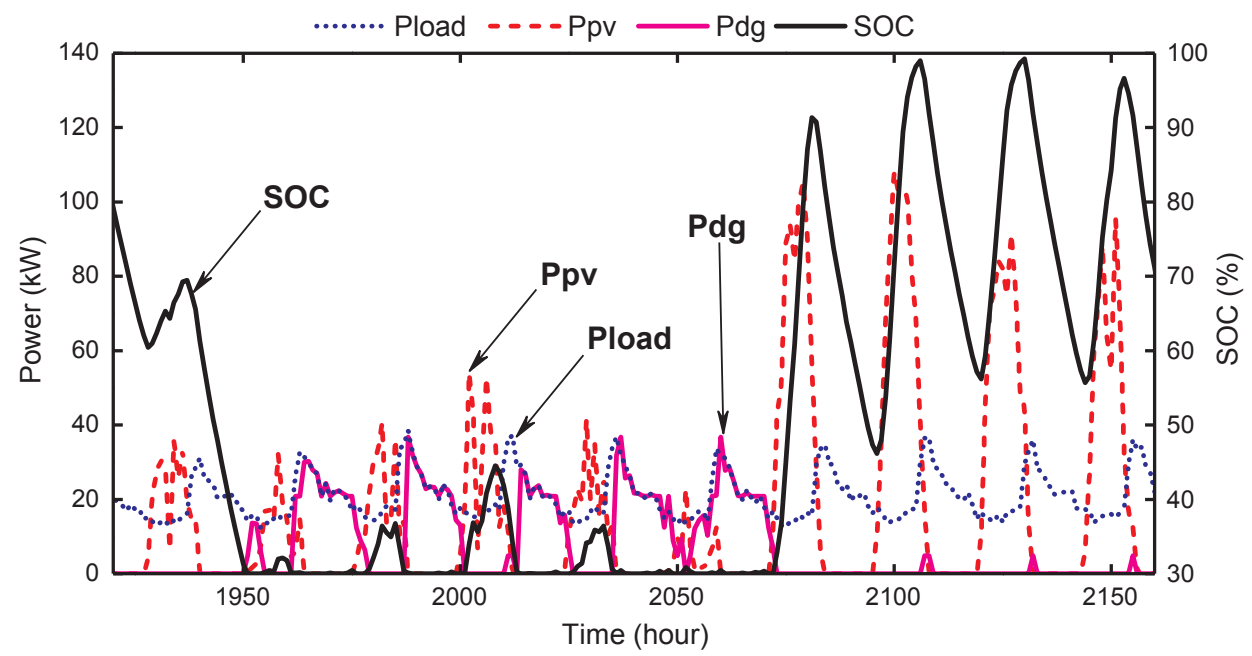

Fig. 11. Hourly simulation of the HPS configuration obtained with the deterministic algorithm (Solution 3 (det.) in Table 8. 


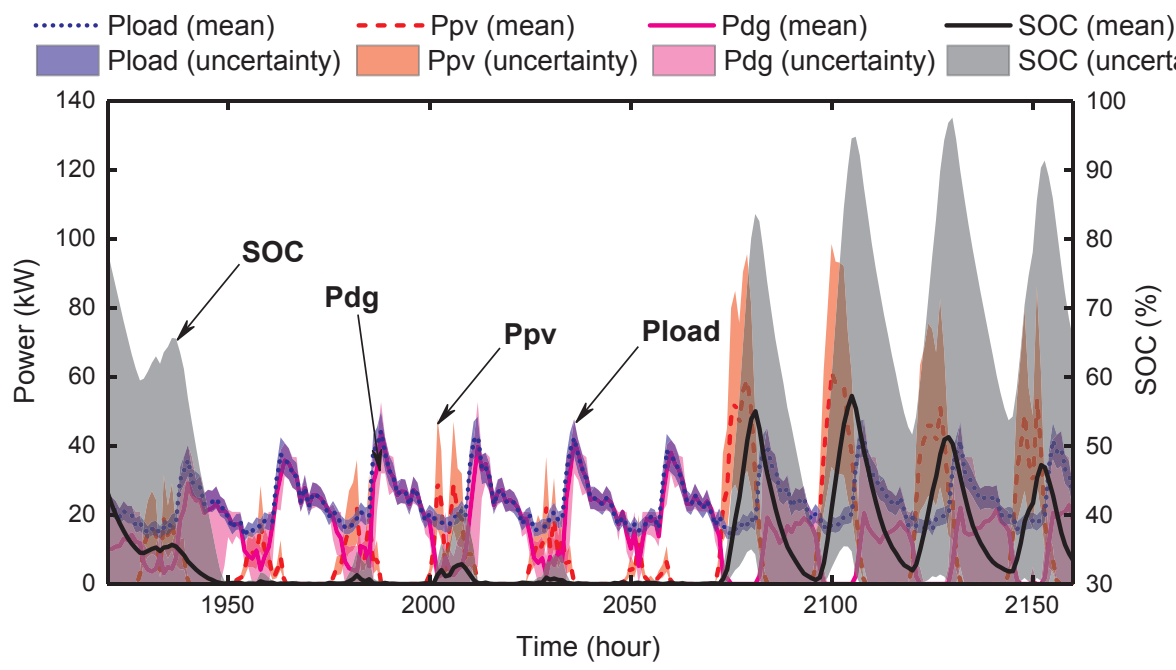

Fig. 12. Hourly simulation of the HPS configuration obtained with the probabilistic algorithm (Solution 3 (prob.) in Table 8 .

battery Hybrid Power System to supply a typical isolated community in the Amazonian region of Brazil consuming $474.9 \mathrm{kWh} /$ day. First, the system was dimensioned considering two objectives, the Net Present Value of costs and the Loss of Power Supply Probability, and the uncertainties were disregarded. This resulted in a deterministic Pareto front where all the solutions obtained include photovoltaic generation, a battery bank and at least one diesel generator. None of the configurations include wind turbines due to the low wind potential present in the region. Despite the high Performance Ratio of PV system, above $76 \%$, there is a need for backup generation to meet the reliability restriction of $5 \%$ maximum energy not supplied.

In a second stage, we studied the influence of the uncertainties in the deterministic configurations obtained before. Three solutions of the deterministic Pareto front were simulated probabilistically introducing uncertainties in the input variables wind speed, solar irradiance, temperature, load demand and components' failure rate. The probability density curve of the Loss of Power Supply shows that the configurations containing a backup generator are more robust in the presence of uncertainties. However, the cost of the system depends on the amount of fuel consumed by the generator, thus the Net Present Value probability curve presents higher dispersion. The average of the deterministic solutions simulated probabilistically move away from the deterministic Pareto front, leading some solutions to violate the reliability constraint. This indicates the need of incorporating the uncertainties within the optimization process.

Finally, the probabilistic approach was used to incorporate the uncertainties within the power system optimization process. Result show that the probabilistic algorithm assigns preference to diesel generation over energy storage, given the generator can be dispatched at request of the system needs. It is observed that a system configuration with the same level of reliability as in the deterministic scenario implies a higher Net Present Value. However, the configurations obtained probabilistically represent feasible robust solutions and guarantee a reliable source of generation.

It is concluded that the probabilistic simulation-based optimization approach allows dimensioning Hybrid Power Systems requiring both optimality and robustness. The method constitutes a useful tool for the decision maker to choose a robust power system configuration obtained in more realistic operating conditions.

\section{Acknowledgements}

The research for this paper was financially supported by the Coordination for the Improvement of Higher Education Personnel (CAPES), through the mechanical engineering post-graduation course

\section{UNESP/FEG (\#33004080027P6).}

\section{References}

[1] Brazilian Institute of Geography and Statistics (IBGE). Sinopse do Censo Demográfico 2010. Domicílios Part Perm Por Exist Energ Elétrica, Segundo as Gd Regiões E as Unidades Da Fed 2010. < http://www.censo2010.ibge.gov.br/ sinopse/index.php?dados $=$ P13\&uf $=00>$ (accessed July 15, 2016).

[2] Goldemberg J, La Rovere EL, Coelho ST. Expanding access to electricity in Brazil. Energy Sustain Dev 2004;8:86-94. http://dx.doi.org/10.1016/S0973-0826(08) 60515-3.

[3] Sharafi M, ElMekkawy TY. Multi-objective optimal design of hybrid renewable energy systems using PSO-simulation based approach. Renew Energy 2014;68:67-9. http://dx.doi.org/10.1016/j.renene.2014.01.011.

[4] Siddaiah R, Saini RP. A review on planning, configurations, modeling and optimization techniques of hybrid renewable energy systems for off grid applications. Renew Sustain Energy Rev 2016;58:376-96. http://dx.doi.org/10.1016/j.rser. 2015.12.281.

[5] Ahmad F, Alam MS. Optimal sizing and analysis of solar PV, Wind, and energy storage hybrid system for campus microgrid. Smart Sci 2017;477:1-8. http://dx.doi. org $/ 10.1080 / 23080477.2017 .1417005$.

[6] Rajbongshi R, Borgohain D, Mahapatra S. Optimization of PV-biomass-diesel and grid base hybrid energy systems for rural electrification by using HOMER. Energy 2017;126:461-74. http://dx.doi.org/10.1016/j.energy.2017.03.056.

[7] Katsigiannis YA, Georgilakis PS, Karapidakis ES. Genetic algorithm solution to optimal sizing problem of small autonomous hybrid power systems. Artif Intell Theor Model Appl Proc 2010;6040:327-32. http://dx.doi.org/10.1007/978-3-642-12842438.

[8] Borges Neto MR, Carvalho PCM, Carioca JOB, Canafístula FJF. Biogas/photovoltaic hybrid power system for decentralized energy supply of rural areas. Energy Policy 2010;38:4497-506. http://dx.doi.org/10.1016/j.enpol.2010.04.004.

[9] Fuso Nerini F, Howells M, Bazilian M, Gomez MF. Rural electrification options in the Brazilian Amazon. A multi-criteria analysis. Energy Sustain Dev 2014;20:36-48. http://dx.doi.org/10.1016/j.esd.2014.02.005.

[10] Gazijahani FS, Ravadanegh SN, Salehi J. Stochastic multi-objective model for optimal energy exchange optimization of networked microgrids with presence of renewable generation under risk-based strategies. ISA Trans 2017. http://dx.doi.org/ 10.1016/j.isatra.2017.12.004.

[11] Maleki A, Pourfayaz F. Optimal sizing of autonomous hybrid photovoltaic/wind/ battery power system with LPSP technology by using evolutionary algorithms. Sol Energy 2015;115:471-83. http://dx.doi.org/10.1016/j.solener.2015.03.004.

[12] Yang YZ, Chen PJ, Lin CS, Wang FC. Iterative optimization for a hybrid PEMFC power system. 2017 56th Annu. Conf. Soc. Instrum. Control Eng. Japan; 2017, p. 1479-84. doi: 10.23919/SICE.2017.8105651.

[13] Sharafi M, ElMekkawy TY, Bibeau EL. Optimal design of hybrid renewable energy systems in buildings with low to high renewable energy ratio. Renew Energy 2015;83:1026-42. http://dx.doi.org/10.1016/j.renene.2015.05.022.

[14] Tafreshi SMM, Zamani HA, Ezzati SM, Baghdadi M, Vahedi H. Optimal unit sizing of distributed energy resources in microgrid using genetic algorithm. In: Proc - 2010 18th Iran Conf Electr Eng ICEE 2010 2010:836-41. doi: 10.1109/IRANIANCEE. 2010.5506961.

[15] Dawoud SM, Lin X, Okba MI. Hybrid renewable microgrid optimization techniques: a review. Renew Sustain Energy Rev 2017;82:2039-52. http://dx.doi.org/10.1016/ j.rser.2017.08.007.

[16] Tezer T, Yaman R, Yaman G. Evaluation of approaches used for optimization of stand-alone hybrid renewable energy systems. Renew Sustain Energy Rev 2017;73:840-53. http://dx.doi.org/10.1016/j.rser.2017.01.118. 
[17] Bernal-Agustín JL, Dufo-López R. Multi-objective design and control of hybrid systems minimizing costs and unmet load. Electr Power Syst Res 2009;79:170-80. http://dx.doi.org/10.1016/j.epsr.2008.05.011.

[18] Markvart T. Sizing of hybrid photovoltaic-wind. Sol Energy 1997;51:277-81.

[19] Chen P-JJ, Wang F-CC. Design optimization for the hybrid power system of a green building. Int J Hydrogen Energy 2017:1-13. http://dx.doi.org/10.1016/j.ijhydene. 2017.12.020.

[20] Rojas-Zerpa JC, Yusta JM. Methodologies, technologies and applications for electric supply planning in rural remote areas. Energy Sustain Dev 2014;20:66-76. http:// dx.doi.org/10.1016/j.rser.2015.07.139.

[21] Al-falahi MDA, Jayasinghe SDG, Enshaei H. A review on recent size optimization methodologies for standalone solar and wind hybrid renewable energy system. Energy Convers Manag 2017;143:252-74. http://dx.doi.org/10.1016/j.enconman 2017.04.019.

[22] Kalinci Y, Hepbasli A, Dincer I. Techno-economic analysis of a stand-alone hybrid renewable energy system with hydrogen production and storage options. Int $\mathrm{J}$ Hydrogen Energy 2015;40:7652-64. http://dx.doi.org/10.1016/j.ijhydene.2014. 10.147.

[23] Kamjoo A, Maheri A, Dizqah AM, Putrus GA. Multi-objective design under uncertainties of hybrid renewable energy system using NSGA-II and chance constrained programming. Int J Electr Power Energy Syst 2015;74:187-94. http://dx. doi.org/10.1016/j.ijepes.2015.07.007.

[24] Lujano-Rojas JM, Dufo-López R, Bernal-Agustín JL. Probabilistic modelling and analysis of stand-alone hybrid power systems. Energy 2013;63:19-27. http://dx. doi.org/10.1016/j.energy.2013.10.003.

[25] Morshed MJ, Hmida JBen, Fekih A. A probabilistic multi-objective approach for power flow optimization in hybrid wind-PV-PEV systems. Appl Energy 2018;211:1136-49. http://dx.doi.org/10.1016/j.apenergy.2017.11.101.

[26] Paliwal P, Patidar NP, Nema RK. Determination of reliability constrained optimal resource mix for an autonomous hybrid power system using Particle Swarm Optimization. Renew Energy 2014;63:194-204. http://dx.doi.org/10.1016/j. renene.2013.09.003.

[27] Katsigiannis YA, Georgilakis PS, Papadopoulos SC, Moschakis MN. Evaluating the performance of small autonomous power systems using reliability worth analysis. In: Proc. PMAPS 2012, Istambul, Turkey: 2012. p. 762-7.

[28] José E, Carlos L, Blasques M, Pinho JT, de Oliveira Barbosa CF, da Silva Pereira E, et al. Manual de Implantação de Sistemas Híbridos Fotovoltaico-Eólico-Diesel. Belém, 2008; 2008.

[29] Tang Z, Périaux J, Bugeda G, Õnate E. Lift maximization with uncertainties for the optimization of high-lift devices. In: 2009 IEEE Congr. Evol. Comput., Trondheim: IEEE; 2009, p. 2324-31. doi: 10.1002/fld.2130.

[30] Deb K, Pratap A, Agarwal S, Meyarivan T. A fast and elitist multiobjective genetic algorithm: NSGA-II. IEEE Trans Evol Comput 2002;6:182-97. http://dx.doi.org/10. $1109 / 4235.996017$.

[31] Dufo-López R, Bernal-Agustín JL. HOGA - Hybrid-Renewable Optimization by Genetic Algorithms; 2015. < http://hoga-renewable.es.tl/ > (accessed May 19, 2015).

[32] Malkawi A, Augenbroe G. Advance building simulation. 1st ed. New York: Spon Press - Taylo \& Francis Group; 2004.

[33] Helton JC, Davis FJ. Sampling-based methods for uncertainty and sensitivity analysis (SAND99-2240). USA: Sandia National Laboratories. Albuquerque; 2000. p. 2000.

[34] Billinton R, Li W. Reliability assessment of electric power systems using monte carlo methods. New York: Springer Science+Business Media, Inc.; 1994.

[35] Manwell JF, Rogers A, Hayman G, Avelar CT, Mcgowan JG, Abdulwahid U, et al Hybrid2 - a hybrid system simulation model: theory manual; 2006:267.

[36] José J, Mendiburu AA, Marotta A, Roberts JJ, Mendiburu AA, Marotta Cassula A Assessment of photovoltaic performance models for system simulation. Renew Sustain Energy Rev 2017;72:1107-23. http://dx.doi.org/10.1016/j.rser.2016.10. 022.

[37] Coskun C, Toygar U, Sarpdag O, Oktay Z. Sensitivity analysis of implicit correlations for photovoltaic module temperature: a review. J Clean Prod 2017;164:1474-85. http://dx.doi.org/10.1016/j.jclepro.2017.07.080.

[38] Lave M, Hayes W, Pohl A, Hansen CW. Evaluation of global horizontal irradiance to plane-of-array irradiance models at locations across the United States. IEEE J Photovoltaics 2015;5:597-606. http://dx.doi.org/10.1109/JPHOTOV.2015. 2392938.

[39] Hocaoğlu FO, Gerek ÖN, Kurban M. A novel hybrid (wind-photovoltaic) system sizing procedure. Sol Energy 2009;83:2019-28. http://dx.doi.org/10.1016/j. solener.2009.07.010.

[40] Nawri N, Petersen GN, Bjornsson H, Hahmann AN, Jónasson K. The Wind Energy Potential of Iceland 2014;16:2014.

[41] Lambert T, Gilman P, Lilienthal P. Micropower system modeling with homer. Integr. Altern. Sources Energy. John Wiley \& Sons Inc; 2006. p. 379-418.

[42] Manwell JF, McGowan JG. Lead acid battery storage model for hybrid energy systems. Sol Energy 1993;50:399-405. http://dx.doi.org/10.1016/0038-092X(93) 90060-2.

[43] Bindner H, Cronin T, Lundsager P, Manwell JF, Abdulwahid U, Baring-gould I. Lifetime modelling of lead acid batteries. vol. 1515. 1st ed. Roskilde (Denmark): Risø National Laboratory; 2005.

[44] Notton G, Lazarov V, Stoyanov L. Optimal sizing of a grid-connected PV system for various PV module technologies and inclinations, inverter efficiency characteristics and locations. Renew Energy 2010;35:541-54. http://dx.doi.org/10.1016/j.renene. 2009.07.013.

[45] Barley CD, Winn CB. Optimal dispatch strategy in remote hybrid power systems. Sol Energy 1996;58:165-79. http://dx.doi.org/10.1016/S0038-092X(96)00087-4.

[46] Turconi R, Boldrin A, Astrup T. Life cycle assessment (LCA) of electricity generation technologies: overview, comparability and limitations. Renew Sustain Energy Rev 2013;28:555-65. http://dx.doi.org/10.1016/j.rser.2013.08.013.

[47] Cartaxo Ferreira E. Fornecimento de Serviço de Energia Elétrica Para Localidades Isolada da Amazônia: reflexões a partir de um estudo de caso. Universidade Estadual de Campinas (UNICAMP); 2000

[48] INMET. BDMEP - Banco de Dados Meteorológicos para Ensino e Pesquisa. INMET Inst Nac Meteorol; 2016. < http://www.inmet.gov.br/portal/index.php?r= bdmep/bdmep > (accessed March 5, 2016).

[49] CRESESB. Potencial Solar - SunData. CRESESB - Cent Ref Para Energ Sol E Eólica Sérgio Brito; 2016. < http://www.cresesb.cepel.br/index.php?section = sundata\& $>$ (accessed March 1, 2016).

[50] Clarke DP, Al-Abdeli YM, Kothapalli G. Multi-objective optimisation of renewable hybrid energy systems with desalination. Energy 2015;88:457-68. http://dx.doi. org/10.1016/j.energy.2015.05.065.

[51] IEA. World Energy Outlook 2013; 2013:708.

[52] IRENA. Off-grid renewable energy systems: Status and methodological issues; 2015:36.

[53] ELETROBRÁS - Centrais Elétricas Brasileiras S.A. Eletrobras - Centrais Elétricas Brasileiras S.A.; 2016. < http://www.eletrobras.com/elb/data/Pages/ LUMIS293E16C4PTBRIE.htm > (accessed August 27, 2014).

[54] Ko M, Kim Y, Chung M, Jeon H. Multi-objective optimization design for a hybrid energy system using the genetic algorithm. Energies 2015;8:2924-49. http://dx. doi.org/10.3390/en8042924.

[55] Paulista UE. Lúcia Bollini Braga; 2014

[56] ANEEL - Agencia Nacional de Energia Elétrica. Indicadores de continuidade, Amazonas Distribuidora de Energia S.A. Divulg Dos Limites Dos Indicadores DIC FIC, DMIC E DICRI; 2016. < http://www2.aneel.gov.br/aplicacoes/srd/indqual/ default.cfm > (accessed May 10, 2016).

[57] Dias EV. Variação Interanual dos Ventos do Nordeste. Universidade Federal de Lavras (MG); 2013

[58] Martins FR, Pereira EB, Guarnieri RA, Silva SAB, Yamashita CS, Chagas RC, et al. Mapeamento dos Recursos de Energia Solar no Brasil Utilizando Modelo de Transferência Radiativa Brasil-SR. I Congr. Bras. Energ. Sol. (I CBENS), Fortaleza, Brasil; 2007.

[59] Silva de Sousa E, Araújo e Silva R, Figueiredo Maciel G, Gomes Nunes R, Lima Borges FW. Variabilidade interanual da precipitação e da temperatura do ar em Teresina-PI no período de 1976 a 2010 visando a captação e armazenamento de águas pluviais. XVII Congr. Bras. Agrometeorol., Guarapari, ES, Brasil; 2011. p. 3-6.

[60] Karki R, Dhungana D, Billinton R. An appropriate wind model for wind integrated power systems reliability evaluation considering wind speed correlations. Appl Sci 2013;3:107-21. http://dx.doi.org/10.3390/app3010107. 